Portland State University

PDXScholar

Summer 9-25-2014

\title{
Evaluation of a High School Science Fair Program for promoting Successful Inquiry-based Learning
}

Julia Nykeah Betts

Portland State University

Follow this and additional works at: https://pdxscholar.library.pdx.edu/open_access_etds

Part of the Educational Methods Commons, and the Science and Mathematics Education Commons Let us know how access to this document benefits you.

Recommended Citation

Betts, Julia Nykeah, "Evaluation of a High School Science Fair Program for promoting Successful Inquirybased Learning" (2014). Dissertations and Theses. Paper 1986.

https://doi.org/10.15760/etd.1985

This Thesis is brought to you for free and open access. It has been accepted for inclusion in Dissertations and Theses by an authorized administrator of PDXScholar. Please contact us if we can make this document more accessible: pdxscholar@pdx.edu. 
Evaluation of a High School Fair Program for Promoting Successful

Inquiry-based Learning

by

Julia Nykeah Betts

A thesis submitted in partial fulfillment of the requirements for the degree of

\author{
Master of Science in Teaching \\ in \\ General Science \\ Thesis Committee: \\ William Becker, Chair \\ Cary Sneider \\ Melissa Potter
}

\title{
Portland State University 2014
}


(C) 2014 Julia Nykeah Betts 


\begin{abstract}
The success of inquiry-based learning (IBL) in supporting science literacy can be challenged when students encounter obstacles in the absence of proper support. This case study is intended to evaluate the effectiveness of an Oregon public school district's science fair coaching program in promoting inquiry skills and positive attitudes toward science in participating high school students. The purpose of this study was to better understand students' perception of program support, obstacles or barriers faced by students, and potential benefits of IBL facilitated by the science fair program. Data included responses to informal and semi-structured interviews, an anonymous survey, a skills assessment of final project displays, and in-depth interviews of three students' experiences. Results suggest that the science fair program can properly engage participants in authentic IBL. However, when assessing the participant's final project displays, I found that previous fair experience did not significantly increase mean scores as identified by the official Oregon Department of Education (ODE) scoring guides. Results of the case study suggest that participants' low science self-concept, poor understanding of inquiry skills, and inability to engage in reflective discourse may reduce students' abilities to truly benefit from the science project support that they receive. Recommendations to address this discrepancy include identifying specific needs of students through a pre-fair survey to develop more targeted support, and providing new opportunities to develop skills associated with science self-concept, understanding of inquiry and reflective discourse. In addition, results suggest that students would benefit
\end{abstract}


from more financial support in the form of grants, and more connections with knowledgeable mentors. 


\section{Acknowledgments}

There are several individuals I would like to acknowledge, and thank wholeheartedly for their support during development, execution, and analysis of my research. Firstly, I would like to recognize Melissa Potter for her encouragement and inspiration in helping me to develop my research question based on pursuits closely following my academic interests. I would like to thank Stephanie Wagner for encouraging me to enroll in the MST program and for her incredible support and flexibility through this transition in my life. In addition, I would like to give thanks to Cary Sneider, who despite his incredibly busy schedule, devoted invaluable time in helping me to write my thesis and better understand my role in this undertaking. I would also like to thank Bill Becker, my committee chair, for his encouragement and thoughtful feedback that helped shape my thesis.

Finally, I would like to acknowledge my colleague, Amy Schauer, for fully supporting an evaluation of our science fair program as a way to improve our students' experiences, and to Jane Stickney, our district's Deputy Superintendent, for insights into our district's goals for improving science literacy and her support in my research. 
Table of Contents

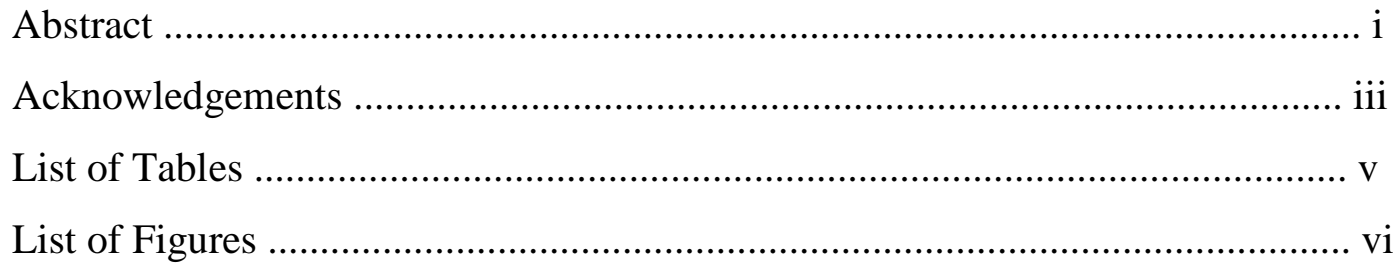

\section{Chapter 1}

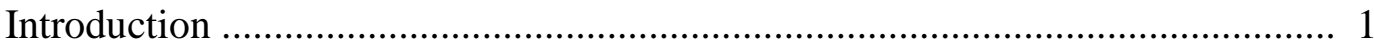

\section{Chapter 2}

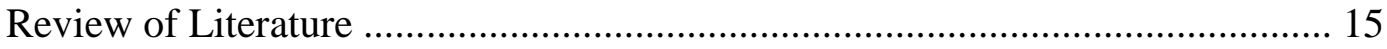

\section{Chapter 3}

Methods

\section{Chapter 4}

Results

\section{Chapter 5}

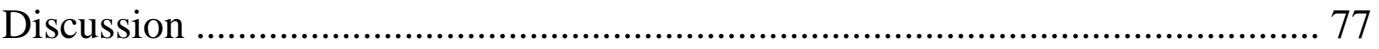

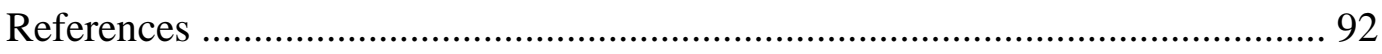

Appendices
A. Pre-fair survey 96
B. Weekly meeting notes 99
C. ODE Science Inquiry and Engineering Design Scoring Guides (2011-2012; High school level) 100
D. Program Assessment Survey 104 
List of Tables

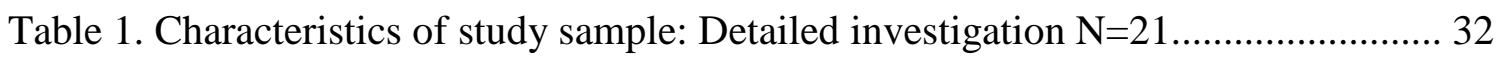

Table 2. Students' motivation for participating in the science fair program; according to Program Assessment $\mathrm{N}=70$..................................................... 41

Table 3. Students' perception of opportunities for reflective discourse according to Program Assessment; $\mathrm{N}=70$................................................................ 43

Table 4. Student responses regarding support offered from knowledgeable mentors/teachers according to Program Assessment N=70

Table 5. Students' perceptions of “Access to Resources” according to Program Assessment $\mathrm{N}=70$ 47

Table 6. Key words/phrases used to search for motivational support" responses from students 48

Table 7. Students' perceptions of helpfulness of "guidelines/structure" according to Program Assessment $\mathrm{N}=70$

Table 8. Coding scheme for "Additional support" suggested by Program assessment respondents

Table 9. Barriers identified by students according to Program Assessment $\mathrm{N}=70$........ 54

Table 10. Skills Assessment of Jessica's Engineering Design project display .............. 64

Table 11. Skills Assessment of Abby's Science Inquiry project display ...................... 71

Table 12. Skills Assessment of Beverly's Science Inquiry project display .................. 76 


\section{List of Figures}

Figure 1. K-12 Framework for Science Education - Practices

Figure 2. Relationship of all components in the science fair program

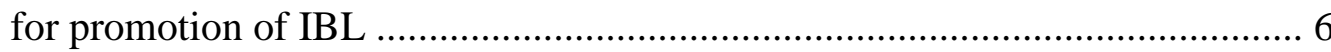

Figure 3. Program Assessment respondents' suggestions for additional support, by category

Figure 4. Comparison, by grade level, of mean Skills Assessment scores for Science Inquiry projects $\mathrm{N}=12$

Figure 5. Comparison, by fair experience, of mean Skills Assessment scores for Science Inquiry projects $\mathrm{N}=12$

Figure 6. Comparison, by grade level/fair experience, of mean Skills Assessment scores for Engineering Design projects $\mathrm{N}=6$

Figure 7. Comparison of mean Skills Assessment scores,

Science Inquiry \& Engineering Design .................................................. 59

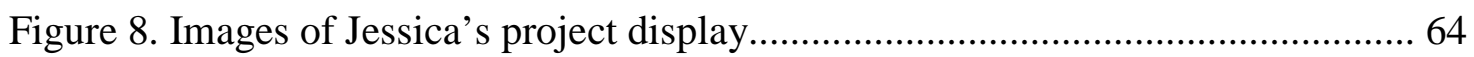

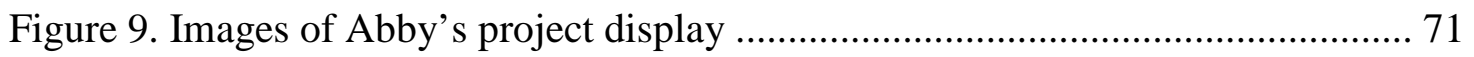

Figure 10. Image of Beverly's project display ............................................... 76 


\section{Chapter 1}

Introduction

The latter half of 2012 held many major transitions in my life that have resulted in a new career path of informal science education. After moving to Portland, and several months of long commutes to Corvallis to my Environmental Scientist position at the United States Environmental Protection Agency (US EPA), I came across an online job posting for an Assistant Program Coordinator for a local high school science fair. I have always been intrigued by the idea of teaching, but was intimidated by the challenges of classroom management or politics associated with formal education. Unlike a teaching position, the role of Assistant Program Coordinator was presented to me as an opportunity to work one-on-one with students, introducing them to the intricacies of scientific exploration, and supporting them in their very own research. As someone with a background in research, I was eager for the opportunity to engage young learners in actual inquiry projects. I myself was inspired to pursue a career in the sciences, in part, by my own high school science fair experience. I decided to accept the school district's offer for the position, and over the next few months I transitioned from full-time employment at the US EPA to a part-time employee as both a scientist and a member of the local school's science fair program.

The science fair program was introduced to the school district in 2002 during a national push to create more Intel International Science \& Engineering Fair (ISEF) affiliated fairs. Through a parent's interest and support by the school board, the program was created to promote student research and make the public school district more 
appealing to "talented and gifted" (TAG) students that might otherwise seek out research opportunities at private schools. As the program developed, more emphasis was placed on ways in which the fair could support incorporation of inquiry into the classroom. Science fair projects have been used as "Science Inquiry" and "Engineering Design" work samples in both middle and high school. After the initial financial support provided by Intel (through affiliation) was exhausted, the district fully committed to funding the program. At all grade levels, students engage in some form of inquiry as supported by the program. At the high school level, students participate in a district-wide extracurricular fair program that culminates in a competitive fair with eligibility to compete at both the state level through the Northwest Science Expo (NWSE) and international level through ISEF. High school students are primarily supported by a Fair Director and me, acting as the Assistant Program Coordinator.

\section{Personal motivation for this study}

My role as the Assistant Program Coordinator is multi-faceted. Aside from managing databases, websites, and organizing many aspects of the fair itself such as donations and awards, my primary duty is to act as a facilitator, or coach, to students participating in the program. In my first year in working with the program, I found the experience incredibly rewarding. It was exciting to work with such an eager group of students. I found that students enjoyed their experience despite the challenges involved in completing their own research. One of the greatest challenges I faced was feeling 
confident in meeting the needs students with such diverse needs. In our weekly meetings, I found that each student might be struggling with a different aspect of their project development, and it was critical for me to identify those needs on an individual basis. In addition, students seemed to struggle with confidence in pursuing their own ideas, or balancing their school work with deadlines from the science fair program. Of greatest concern to me were students that eventually dropped out of the program, and were unable to complete their projects. I became very curious as to why students were dropping out of the program, and if any interventions by the program coaches might improve retention rates. I was also curious to find out the exact barriers that students were facing throughout the process, and what our team could do to improve support. I administered an anonymous post-fair survey to gather feedback from the students about their experiences. I found it incredibly valuable to offer students the opportunity to reflect on their fair experience, as well as connect with their role as a driving force in the process. My curiosity into the value of the science fair experience for program participants also ignited an interest into whether or not our program has the intended outcome of facilitating successful inquiry.

Science fairs and the Next Generation Science Standards (NGSS)

In addition to providing TAG students with opportunities to engage in self-driven research, it is also the intention of the program to support all students in inquiry based learning. Research suggests that engagement in in-class scientific investigations, science 
fair projects, and laboratory studies give students the opportunity to develop "conceptual learning, techniques and manipulative skills, investigative skills, and affective outcomes" such as improved attitudes toward science and critical thinking skills which can be applied to all aspects of a students' educational process (Wilkinson and Ward 1997). Inquiry based learning has been shown to improve attitudes, promote problem-solving skills, and develop an understanding of the nature of science that might not otherwise be gained from conventional or traditional science education (Hofstein \& Lunetta 2003, Dolan \& Grady 2010, George 2003).In accordance with recent statewide adoption of NGSS, there is a greater need for more opportunities to engage students in such hands-on experiences involving both scientific and engineering practices. Through our fair program, students are offered the opportunity to explore a broad spectrum of disciplines, including sociology, ecology, plant and animal sciences, chemistry, physics, computer sciences, electrical/chemical/civil engineering, human health, math, and microbiology. Specific to the science fair experience, it is the intention that students will gain valuable inquiry skills as identified in the NGSS practices, highlighted by the opportunity to intelligibly communicate their findings during the fair itself (Figure 1) (NRC, 2012, p. 42). 
Figure 1. K-12 Framework for Science Education - Practices

\section{PRACTICES FOR K-12 SCIENCE CLASSROOMS}

1. Asking questions (for sclence) and defining problems (for engineering)

2. Developing and using models

3. Planning and carrying out Investigations

4. Analyzing and Interpreting data

5. Using mathematics and computational thinking

6. Constructing explanations (for sclence) and designing solutions (for engineering)

7. Engaging in argument from evidence

8. Obtaining, evaluating, and communicating Information

I wanted the opportunity to explore whether our students are utilizing these practices through participation in the science fair program. Although both science and engineering are represented at our fair, science projects take up the greatest proportion. For the 2014 fair, for which this study was conducted, only 26 of the 124 projects $(21 \%)$ were engineering-based. With this in mind, greater emphasis was placed in science inquiry projects throughout this study design.

\section{The role of a Science Fair Program in IBL}

Researchers suggest that promoting reflective discourse in an informal atmosphere between peers and mentors can promote a healthy learning environment "conducive to meaningful inquiry" (Hofstein \& Lunetta 2003). In addition, students with adequate support from knowledgeable teachers, access to necessary resources, and motivational 
support which fosters science self-concept, all play a critical role in nurturing productive IBL (Akinoglu 2008, Syer and Shore 2001). Although students have been found to benefit from this type of support, many schools are unable to offer extra coaching for science fairs, especially when participation in the fair is extracurricular (Akinoglu 2008, Syer and Shore 2001).

Through my Masters in Science Teaching program at Portland State University, I had the opportunity to develop a study in order to further explore our science fair program's effectiveness in promoting successful inquiry based learning. In order to properly evaluate the success of the program, it was necessary to determine the relationship between the program, participant, and inquiry-based learning (IBL) as the intended experience (Figure 2).

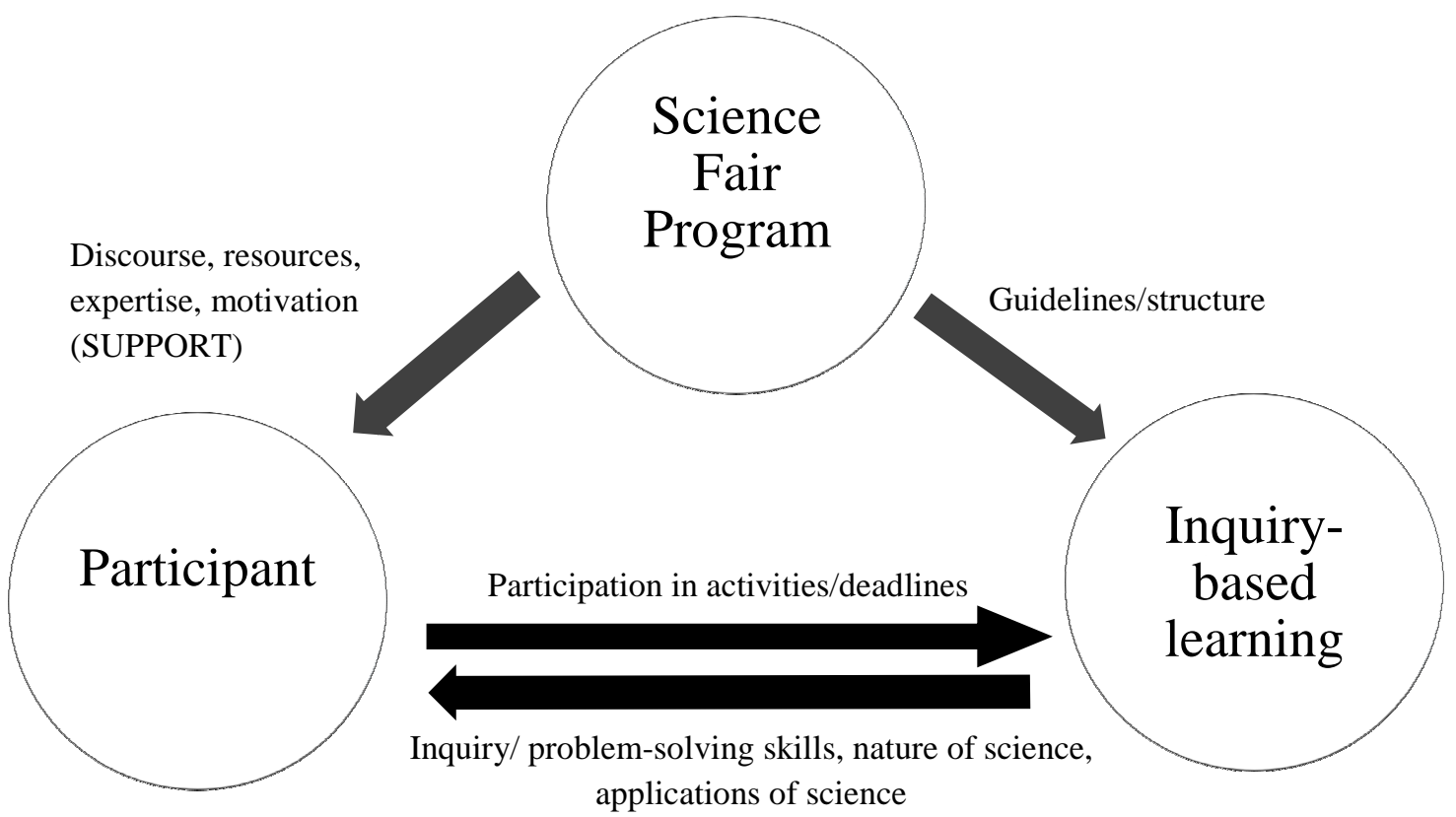

Figure 2. Relationship of all components in the science fair program for promotion of IBL 


\section{Who comprises the "Science Fair Program"}

Coaches are the primary facilitators of the science fair process, and most commonly have the greatest amount of interaction with students throughout the program. Alongside Amy Schauer, the Fair Director, I work to support students throughout each stage of their inquiry process, from deciding on a topic, to executing their experiments, to presenting their finding to the public.

The program is also supported by science teachers who act as "Adult Sponsors," responsible for reading research plans and engaging the participants in conversation about their work. In some cases, adult sponsors will work with students to set up their experiments or help in gathering participants where applicable. Adult sponsors are also responsible for assisting in the complete of ISEF-required forms. Science teachers also volunteer to act as "judges" for the practice symposium, in order to prepare students for the official fair judging.

Although it is not necessarily offered every year, for the 2013-2014 school year, three science teachers from each high school were given "extra duty" contracts to act as category-specific mentors. For the categories of Microbiology, Physics/Engineering, and Chemistry, teachers were recruited to support students with lab techniques, safety, and design. In addition, a math teacher at each school was contracted for 0.25 FTE to support students with statistical analysis. 
For several students, a "Mentor" may be recruited, having specialized training in a given area that is beneficial to the project's success. Mentors may be researchers, business leaders, or educators of a variety of disciplines. Typically, initial contact with a mentor is facilitated by a coach, and students are encouraged to work in their mentor's lab or facility if possible. Not all students are connected with, or require a mentor, and in some cases it is difficult to find a person that can best act as a mentor for a particular project. For the 2014 science fair, 38 out of 124 projects were supported in some way by a mentor.

Additional volunteers help the program coaches with fair organization, including judge recruitment, catering of the event, and fundraising, but they do not work directly with the students.

In this study, I played the role of coach and evaluator. I gathered feedback from students primarily regarding their interactions with myself, and the Fair Director, Amy Schauer, although the helpfulness of support from Adult Sponsors and other teachers was addressed. Support from mentors was not explicitly explored during this study.

\section{What the "Science Fair Program" has to offer Participants}

Support offered to the student can be characterized by four different attributes of the program: opportunities for reflective discourse, expert advice from knowledgeable adults, access to resources, and motivational support. 
Opportunities for reflective discourse in an informal atmosphere. Through weekly meetings, emails, phone conversations, and after school hours, we supported students in developing their own research, discussing with them their role as an "expert" in their topic. Coaches performed weekly meetings in an informal setting rather than a classroom, and students were free to discuss their ideas and challenges with mentors. Discussions with peers were encouraged through online forums and social media.

Expert advice from knowledgeable teachers/mentors/coaches. When appropriate, coaches connected students to mentors or professional scientists that could support them in their research. This was done through initial contact via email or phone-calls, followed up by informal meetings or tours of different facilities. Based on a student's research topic, they were either assigned or chose an "Adult Sponsor", typically a science teacher, who worked directly with the student in developing their project idea and executing their experiments or design. Students in the fields of Engineering/Physics, Chemistry, and Microbiology were assigned a specific science teacher that was contracted by the Fair Director. These teacher mentors provided expert advice and scheduled laboratory time. Coaches were also available as adult supervisors for after school or weekend project work when science teachers or other mentors were not available.

Access to resources, such as materials, lab space, and technology. The greatest proportion of our coaching time is spent in support of students' execution of the science fair process. In addition to ordering necessary supplies and helping to organize materials we worked to organize lab space and equipment necessary for experimentation. We also 
supplied assistance in the form of "inquiry empowering technologies" such as Vernier probeware, statistical analysis tools, and other such resources (Hofstein and Lunetta, 2003). If requested by the students, occasional informative workshops were offered to teach basic laboratory techniques (e.g. bacterial culturing). Registration fees for the fair as well as the cost of many materials needed are paid for by the school district. In addition, a need-based reimbursement grant is offered to all students.

Motivational support that fosters science self-concept. As coaches we encouraged students when they were faced with issues, and did our best to maintain a positive environment. We acknowledged when students encountered emotional or psychological barriers to their learning experience, and attempted to mitigate these challenges. Specifically, we offered encouragement when students felt discouraged because their hypothesis was not supported by data, or they faced challenges in interpreting results based on incomplete experimental design.

How the "Science Fair Program" helps students develop IBL: Structural guidelines for engaging in IBL

We provided information packets to all students at different stages of the process, which acted as guides to scaffold the IBL experience. Packets included suggested timelines, explanations of key components of a project, resources and tips for experimental design and data analysis, etc. In addition, we set deadlines associated with 
submission of forms, and key components of their research plan, in order to keep students on track and support healthy time management skills. Program coaches assisted in completing forms necessary for fair registration, and made students aware of projectspecific guidelines when working with hazardous materials, human test subjects, and other projects requiring Scientific Review Committee (SRC) approval.

\section{What IBL has to offer Participants}

One of the key goals of the science fair program is to give students the opportunity to engage in self-directed inquiry. Although students are introduced to IBL at the primary level in this district, it is only when students reach high school that they are given complete creative license in developing their own idea. The intention is that students will gain personal insights into the steps necessary for experimentation and have the opportunity to acquire skills and abilities pertinent to conducting tests. Students work in an authentic laboratory setting and are able to utilize different equipment and specialized instrumentation they are not likely to encounter in the classroom. We also help student to improve upon their problem-solving skills as they face the challenges associated with carrying out an investigation in which they are the principal investigators. Engaging in self-directed inquiry in an extracurricular setting gives students the opportunity to apply scientific content knowledge acquired in a classroom setting to personal interests. These opportunities may offer students a better understanding of the 
applications of science as well as an improved understanding of the nature of science (Akinoglu, 2008).

Responsibilities of Participants

Students interested in participating in the fair are expected to engage in specific activities throughout the process. As the driving force in their learning experience, students are expected to utilize support from the science fair program to establish personal goals and timelines for completion of their project. Students were asked to report on progress of different components of their project, including their background research, draft research proposal, experimental design, and appropriate forms necessary for experimentation according to rules associated with an ISEF-affiliated fair. A specific benchmark the students were responsible for making in order to complete the science fair process was submission of necessary forms for participation (parental consent, human subjects, potentially hazardous materials, etc). In addition students were required to submit a completed Research or Engineering Proposal with clearly defined Research Question or Engineering goal, Hypothesis, Introduction, Background Research, Procedure, and Risk Assessment. Research plans must be approved by program coaches, and in some cases by the SRC, before experimentation could begin. Participants were also required to officially register for the fair online, attend one of two practice or "mock" symposiums, and present their findings at the regional science fair to judges, peers, and the public throughout the three-day fair. 
This design is intended to give students the opportunity to engage in an authentic inquiry process in which they make all the key decisions. Students decide on their research topic, perform searches for background information, design their experiments, collect and analysis data, and communicate their findings in an informed and professional manner at the regional science fair. Participants of the program are required to complete all these steps in order to qualify for in-class or elective credit for their project.

The intention of my study is to evaluate the potential success of a science fair program in supporting IBL by answering the following research questions:

- How does a student's initial motivation or level of involvement influence their utilization of support offered by the program?

- In what ways did our students benefit from support offered by the program?

- What barriers were most challenging to overcome for our students?

- In what ways did students that participate in the science fair program exhibit proposed benefits of IBL, such as improved problem-solving skills or a better understanding of the nature of science?

I answered these questions by gathering feedback from students regarding their motivation for participation, the helpfulness of program support, and barriers they faced throughout the process. This was done through informal interviews throughout the fair process, semi-structured exit interviews, and an anonymous survey. In addition, I 
explored the role that the science fair program plays in directly facilitating successful IBL through interview, an assessment of students' project displays, and a series of individual profiles of participant's fair experience and inquiry skills as related to help they received from the science fair program.

With this information, I intended to learn about specific barriers that our students face throughout the fair process, and what interventions, if any, the district can offer to encourage future enrollment in the program through mitigation of such barriers. Moreover, my findings from this evaluation could suggest improvements to our program, and also act as a resource to other district leaders who are curious about the value of their science fair, and may wish to know what resources are most effective in supporting IBL and achieving science education goals. 


\section{Chapter 2}

\section{Review of Literature}

The National Science Education Standards (National Research Council, 1996) suggests that when used properly, "laboratory is especially important in the current era in which inquiry has re-emerged as a central style advocated for science teaching and learning" (NRC, 1996, pg 23). In this literature review, I summarize articles which further explain IBL as a tool for science literacy, an exploration of science fairs as examples of IBL, and barriers of and appropriate support for students' engagement in successful science inquiry.

\section{IBL as tool for science literacy}

In a review spanning 20 years of research and literature, Hofstein and Lunetta (2003) evaluate the changes to expectations of science education and the role that laboratory work plays in supporting science literacy. Laboratory activities, when done properly, give students the opportunity to "study the natural world, propose ideas, and explain and justify assertions based upon evidence derived from scientific work" in the same manner that scientists engage in authentic inquiry (Hofstein \& Lunetta, 2003, p 30). Such an introduction to "central conceptual and procedural knowledge and skills in science" is critical to supporting science literacy (Hofstein \& Lunetta, 2003, p 31). Science education goals that are supported by laboratory activities include understanding 
of science concepts, interest and motivation, scientific practical skills, problem solving, and an understanding of the nature of science. Students without time or opportunity for metacognitive activities are less successful in applying such skills long term. In addition, IBL should be student-directed, with opportunities for the students to improve upon their science self-concept and attitudes toward science. Hofstein and Lunetta cite Polman (1999) to support their view that if science learning is to be fostered through projects and inquiry, teachers and authority figures must play a complex role in discourse with their students. An informal atmosphere and opportunities for interactions between peers and mentors can promote positive social interactions and a healthy learning environment “conducive to meaningful inquiry" and collaborative learning. (p 36) The researchers suggest that there is a need for frequent opportunities for feedback, reflection, and modification of their ideas. In additional studies, researchers noted that those opportunities don't exist in most schools in the US (Tobin, 1990; Polman, 1999). “If students' understandings are to be changed toward those of accepted science, then intervention and negotiation with an authority, usually a teacher, is essential" (Driver 1995). Hofstein and Lunetta (2003) also discuss the need for "Inquiry Empowering technologies" such as computers, probe ware, and availability of instrumentation that aids in students' development of analytical skills, as well as a need for appropriate assessment of lab work and activities in order to evaluate how effective lab guides and current curricula are in supporting science education goals. 
Researchers and educational consortiums alike suggest the incorporation of "authentic inquiry" in which students "choose research question, variables, procedures, and must explain their results in light of other studies and theories" (Brickman 2009). Beyond these skills, it is suggested that IBL may help to encourage "derived science literacy" in which students have the ability "to transfer conceptual understanding and accurately interpret and evaluate texts dealing with scientific concepts" (Norris et al 2003). In a 2009 study, researchers from the University of Georgia led by Brickman evaluated the effects of IBL on undergraduate college students' science literacy skills and confidence (Brickman, 2009). Specifically, the researchers wanted to measure "changes in science literacy, science process skills, and self confidence in doing and writing about science." Two groups of students were instructed for an Introductory Biology lab course using the traditional instruction methods or using an IBL design the researchers developed. To assess each type of instruction, students were evaluated based on responses to a Science Process Skills Assessment, a Self-Efficacy survey (pre- and post test), course evaluations submitted by students, and group interviews after the duration of instruction. Overall, students preferred the traditional, canned lab experience because it was easier, despite the fact that they "wouldn't learn as much." However, students found that "collaborative aspects of struggling together were both rewarding and frustrating." Although challenging, students found the inquiry based laboratory structure representative of a more authentic scientific experience. Based on the Science Process Skills Assessment, the researchers found greater improvements in students' science 
literacy and research skills when using inquiry based instruction, despite a lower selfconfidence in their science abilities.

In a similar comparative study, performed by Wilkinson and Ward (1997) in Victoria, Australia, researchers wanted to examine the perceptions of Year 10 students and their science teachers with respect to lab work. Researchers proposed that lab work helps to develop "conceptual learning, techniques and manipulative skills, investigative skills, and affected outcomes." The desired affective outcomes of lab work, or IBL, include "attitudes to science such as interest, enjoyment, satisfaction, motivation, as well as thinking, objectivity, critical-mindedness, skepticism, and willingness to consider evidence" (Gardner and Gauld, 1990). 139 Students and their teachers (six in total) were interviewed regarding their personal experience and attitudes toward the effectiveness of lab work in supporting authentic science. Overall, students did not think that lab work was relevant to everyday life. They were not actually encouraged to do their own experiments, and "most teachers said that they encouraged only their better, more trustworthy students to do investigative work on their own." (Wilkinson \& Ward, 1997). Because of this lack of personalization, students had a very different perception of the purpose of science inquiry, "often fail[ing] to see the connection between the prepared laboratory activities and the content to be learned." The researchers concluded that in order for lab work to support such science literacy components as investigative skills and interest toward science, it is highly critical for teachers to make the definition of lab work 
explicit, and to engage students in their own research in which relevance to the real world is emphasized.

One way in which institutions have chosen to tackle the need to personalize IBL is through science fairs. Students are required to define their research, design their experiment, collect data, and present their findings, utilizing many inquiry skills specific to the emerging framework for science education. "At all levels, they [students] should engage in investigations that range from those structured by the teacher-in order to expose an issue or question that they would be unlikely to explore on their own (e.g., measuring specific properties of materials) — to those that emerge from students' own questions.” (NRC Framework, 2012, p. 61)

\section{Science fairs as IBL}

In a 1996 study performed by Schneider and Lumpe, 41 teachers of students (grades 7-12) participating in the Ohio Academy of Science's District 2 fair were directed to complete a survey evaluating the success of science fairs in supporting key science education goals. The researchers identified these goals as: exploration of a real world issue important to the student, hands-on/minds-on, scientific knowledge, scientific inquiry, higher order thinking, habits of mind, integration or the interrelatedness of science disciplines, and social skills. In addition, the researchers utilized their survey to examine potential factors that may influence the effectiveness of science fairs in 
supporting science education goals, including: team versus individual projects, teacher modeling of projects, student support by parents and other adults, school attendance at a regional science fair, and grade level. Teachers reported an overwhelmingly positive response of science fair participation on achievement of science education goals. The researchers found that teacher and parental support appeared to positively influence the teachers' overall perception of science fairs as a successful tool for improving science literacy. This study also reflects the perceived success of achieving education goals by educators themselves, and does not interview the students directly.

A study performed in 2003 by Senay Yasar aimed to examine the impact of science fair participation on understanding and attitudes toward science of $7^{\text {th }}$ grade students by directly asking students of their experiment rather than their teachers. Preand post-tests (instruments) were assigned to two different groups, students that participated in a science fair and those that did not. Although test scores for both science understanding and attitude were higher for students participating in the fair, the scores were not significantly higher based on the large variance of the comparison group $(\mathrm{N}=$ 379 for pretest and $\mathrm{N}=430$ for posttest versus $\mathrm{N}=24$ and $\mathrm{N}=26$ for experimental group). It was noted that post-test scores for both groups were lower, implying a poorer understanding and attitude toward science after the time period associated with a science fair, regardless of participation. The researcher suggests that additional research as to the efficacy of science fairs be explored, specifically evaluating how a students' attitude toward science may influence their perception of IBL such as that provided by science fairs. 
One such study was performed in 2003 by George, evaluating changes in students' attitudes regarding the utility of science over the middle school and high school years. Researchers performed a latent variable growth modeling of previously acquired data from student questionnaire answers to a Longitudinal Study of American Youth (LSAY). The important predictors of attitudes about the utility of science were identified as: science self concept, teacher encouragement of science, achievement motivation and science activities (such as science fairs), peer attitudes, and parent support. "Attitudes influence the students' academic achievement in science as well as their selection of science careers" (Sorge et al 2000). The researchers extracted data from the LSAY, following 444 students' progression from $7^{\text {th }}$ to $11^{\text {th }}$ grade with respect to survey answers about their attitudes of science and their predictors. The results of the analysis show an overall increase in attitude toward the utility of science as students go from $7^{\text {th }}$ through $11^{\text {th }}$ grade. Self concept had the greatest effect on students' attitudes. The next strongest predictor was students' perceptions about the amount of encouragement they got from their science teachers. There was also a positive association between science activities and attitudes, as "it is found that participation in science activities such as science fairs, and science clubs, are associated with higher attitudes about the utility of science." Students that engaged in activities such as science fairs and those that perceived support from their teachers had increasingly positive attitudes of science which is suggested to improve their overall performance and understanding of scientific concepts.

There are conflicting results surrounding the influence of science fairs on students' attitudes toward science, and its connection to the proposed benefits of IBL. 
These conflicts may result from differences in specific obstacles, and means to overcome those barriers, that students face when engaging in inquiry. The following studies explore the types of barriers that students encounter during IBL and the most successful types of support students receive.

Barriers of and appropriate support for students' engagement in successful science inquiry

In an investigation performed by Pyle (1996), high school student researchers from the $44^{\text {th }}$ International Science and Engineering Fair (ISEF) were interviewed on the day of the fair regarding the influences on their design and their motivations for completing a successful project. Students reported that the ability to "take ownership" of their own project design is critical to their perceived success. Pyle notes a flaw in their own design study, suggesting that more information should be gathered (pre- and posttests) rather than singular interviews at the day of the fair. A study on potential outside influences that may shift a student to design an experiment based solely on the likelihood to win rather than based on personal curiosity or exploration should be considered. Only the highest achieving participants were interviewed and their motivations for participating were primarily based on achievement in the form of awards. This promotion of competition may not be a suitable motivation factors for all participants, leading to withdrawals or reduced participation. 
The potential benefits of science fair participation have been explored and affirmed by educators (Schneider \& Lumpe 1996) but research performed by Czerniak and Lumpe (1996) found that students' motivation for participation was not overwhelmingly based on a pursuit of knowledge or competition. In the study, factors which may influence participation in a science fair were predicted using The Theory of Planned Behavior (TPB) as developed by Ajzen \& Madden (1986). The researchers intended to determine what factors predict students' attitude toward a science fair, and factors influencing perception of approval and control with respect to participation. Answers to a TPB questionnaire (by eighty 7-12 grade students) reflected the students' belief that while science fairs were a good opportunity to learn something (54\% of students) and a great way to receive extra credit or improve one's grade (28\%), fairs wasted time (61\%), and required undesirable amounts of "hard work" (20\%). 81\% of students reported that participation in the science fair was required, and $77 \%$ of students reported that a score was received on their projects, suggesting that the students' behaviors toward participating were driven by grades or a motivation to comply with rules more than a desire to learn. The researchers suggest that additional research is performed to examine the influence of mandatory participation in a science fair on students.

In a similar study conducted by Czerniak (1996), the researcher examined the potential influence that specific factors have on success at a regional science fair. Czerniak postulated that similar concepts with respect to factors influencing academic success (such as self concept, parental influences, motivation, anxiety, and selected 
demographic values) apply to science fair success. "Success" at a science fair was defined by the relative score awarded to each project by the fair judges, and each factor was measured through answers to a questionnaire mailed to participants after the fair. Application of a discriminant function analysis to student questionnaire results found a "pressure to succeed" strongly correlated with student success. Students required to complete a science fair project ( $84.5 \%$ of 142 students), or those that reported the project counting toward a grade $(92.3 \%)$ were "motivated" to complete a successful project through parental and school pressure rather than pursuit of knowledge. The results also suggested that parental pressure and the use of the project as a grade may have negatively affected students' science self-concept, or their confidence toward and general interest in science. However, based on their study, the researchers stated it was "unclear how participation in science fairs subsequently affects science self-concept" and they suggest additional research be performed on this topic.

A study was performed by researchers in Istanbul, Turkey, in order to assess students' perception of the inquiry-based project implementation process and how it influences many factors, including self-concept and performance in science (Akinoglu 2008). In this study, one-hundred $6^{\text {th }}-8^{\text {th }}$ grade students, from 24 different schools, were interviewed during their active participation in science projects. Based on their interviews, researchers discovered several challenges that students associated with completing a project. Students were not typically inspired by their "own interest areas" (only 10 students were motivated by personal interests) to decide a topic, and relied on previously developed experiments they found online. $29 \%$ of students found that finding 
a topic was the most difficult part of their project. In addition, $37 \%$ of students mentioned time limits are a significant issue. Although students also recognized that issues in finding sources caused delays in progress with their project, the most noticeable "main problem" that students identified was communication with their teachers. The students $(36 \%)$ felt that their teachers were not knowledgeable about the process, and could not adequately support their research. Despite describing several shortcomings to the process, students self-reported that engaging in the inquiry process made them "more interested in their science and technology classes" (47\%), they "developed creative thinking skills" $(27 \%)$, and noted a rise in their self-confidence $(11 \%)$. Some students attributed an increase in science class grades (38\%) to their involvement in the inquiry project process, although $21 \%$ of students noted a decrease because they needed to "work hard for science projects." Overall, the researchers concluded that while there were numerous barriers that students faced during their inquiry process, the proclaimed improvement to science selfconcept and interest was a critical aspect of IBL that should be encouraged by teachers. The researchers concluded by stating that "the success of inquiry-based active learning depends on whether the required materials, environment, socio-psychological support and teaching guidance are offered."

Syer and Shore (2001) surveyed 24 Canadian high school students involuntarily enrolled in their school science fair in order to determine the types of help that students received (and were aware of) during the process, the challenges they faced, and what measures they took to overcome them. Specifically, the researchers wanted to take a 
closer look at pressures to succeed, and the potential for cheating in science fairs. Some of the greatest obstacles the students described were pressure, disappointment or fear of failure, the difficulty in coming up with ideas, and staying motivated. Most of the help students received was from the internet (22 of 24) and from parents (21 of 24). Students deemed other resources "fair" to use, including teachers, libraries, fellow students, siblings, etc. but did not take advantage of these resources. Overwhelmingly, the students did not use teachers for help during their projects. The students found that teachers lacked time, knowledge, and even a willingness to help. Of the 24 students, five admitted to cheating on their science fair project, either through copying someone else's work or making up data. The researchers suggest that if the students perceived the teacher as unavailable, perhaps they also believed that this was a project not to be taken seriously. In this case study, students were responsible for doing all lab work outside of the classroom, and curriculum was content-driven due to assessments, so very little attention was given to the science fair projects. The researchers suggest that considerations should be made for time limitations, pressure associated with science fair competition, and improvements to support that students are given.

\section{Closing summary}

IBL has consistently shown promise in supporting key science education goals such as development of problem solving and investigative skills, and an understanding of the nature of science (Hofstein and Lunetta 2003). Researchers have also found that engagement in IBL improves students' attitudes toward science which is related to their overall science achievement (Wilkinson and Ward 1997). Science fairs have been shown 
to adequately support science education goals based on teachers' perceptions (Schneider and Lumpe 1996) and participation in science fairs has been shown to improve students' attitudes toward science (George 2003).

The effectiveness of a science fair program to represent IBL and its projected benefits is dependent on many key factors. Students face obstacles such as time limitations, pressure to succeed, motivations other than curiosity, fear of failure, and challenges in acquiring the skills necessary to complete their project (Czerniak 1996, Czerniak and Lumpe 1996, Pyle 1996). However, research suggests that appropriate guidance from mentors and teachers, availability of resources, and "socio-psychological support" can support a successful IBL experience for students (Akinoglu 2008, Syer and Shore 2001).

By studying the effectiveness of the science fair program, I will be afforded the opportunity to examine:

- A student's initial motivation or level of involvement and its influence on their utilization of support offered by the program

- Ways in which our students benefited from support offered by the program

- Barriers that are most challenging to overcome for our students

- The potential relationship between support offered by the science fair program and proposed benefits of IBL, such as improved problem-solving skills or a better understanding of the nature of science

This research will inform our district as to the effectiveness of our program, what specific barriers students may face, and how those barriers may influence their successful 
completion of a science fair project. In addition, my research can help to inform other school districts that are interested in developing a science fair coaching program on the specific types of support that are most valuable in encouraging authentic inquiry experiences. 


\section{Chapter 3}

\section{Methods}

\section{Overview}

I determined that a mixed-methods evaluation is the most appropriate approach for comprehensively investigating the effectiveness of my school district's science fair program. I gathered data on students' motivation for participating, perceptions of support offered by the program, and barriers they faced using an anonymous Program Assessment survey. An examination of the program's success in promoting IBL was performed through semi-structured interviews (Bryan \& Glynn, 2011), examination of weekly meeting notes and an assessment of participating students' final project displays. I examined the success of the fair program in facilitating IBL through an in-depth analysis of a subsample of participants, including interviews and an assessment of their project displays. In addition, I developed profiles of three individual participants in order to examine the potential relationship between support offered by the science fair program and a student's inquiry skills and perceptions of science. 
The diagram below represents the chronology of the study:

$\begin{array}{llllllll}\mathrm{P}_{\mathrm{i}} & \mathrm{P}_{\mathrm{p}} \mathrm{X}_{\text {project }} & \mathrm{O} & \mathrm{P}_{\mathrm{o}} & \mathrm{X}_{\text {fair }} & \mathrm{S}_{\mathrm{A}} & \mathrm{I} & \mathrm{P}_{\mathrm{A}}\end{array}$

Key:

$\mathrm{P}_{\mathrm{i}}=$ Program introduced to students; by teacher/mentor/peer

$\mathrm{P}_{\mathrm{p}}=$ Program pre-registration, informal survey used to setup meeting times

$\mathrm{X}_{\text {project }}=$ Participation in a science fair project

$\mathrm{O}=$ Informal interviews/weekly meetings/coaching/experimentation

$\mathrm{P}_{\mathrm{o}}=$ Program official registration, commitment to present $/$ compete

$\mathrm{X}_{\mathrm{fair}}=$ Presentation of a project at the science fair

$\mathrm{S}_{\mathrm{A}}=$ Skills Assessment of project display

$\mathrm{I}=$ Interviews

$\mathrm{P}_{\mathrm{A}}=$ Program assessment - survey in which students offer feedback on their overall experience

Participants

I carried out the evaluation in three different high schools within a school district in a metropolitan area of northwestern Oregon. According to the district website as of March 13, 2013, enrollment of high school students for the 2013-2014 school year was $2,712.17 \%$ of students in the district in question receive reduced price lunches. The most common ethnicities are White, non-Hispanic (79\%) and Hispanic/Latino (10\%) (Oregon Department of Education School District Annual Report Cards, 2013). Students participating in the study were from 9-12 grade, ages 14-19, and registered for the district's regional science fair. 
Science Fair Program Participants. From the district-wide high school student body, 310 students, representing 226 projects, showed an interest in participating in the fair, either through pre-registration, discussions with science teachers, or informal meetings with the fair coordinators. On the day of the fair, 124 projects were presented by 197 students, representing two of the three high schools. Of the 197 students who presented at the fair, 72 did so voluntarily, 42 were required to present for a grade in their science class, and 83 received in-class credit for their projects.

Study Participants: Program sampling. Participants of the anonymous Program Assessment totaled 70 students, including 62 students that had completed the science fair program, and eight students that did not present their projects at the fair. Twenty-one students offered consent to participate in a more thorough examination of their fair experience through Interviews and a Skills Assessment of their final project displays, representing 18 projects that presented at the fair and one that did not. Of those interviewed, ten students did their project with a partner, and 11 students worked alone. 15 were female and six were male, and there were 13 science inquiry participants, and eight engineering participants (Table 1). All students taking part in the interview process participated voluntarily in the program, and eight students used participation in the fair to replace an inquiry-based project in their science class. 
Table 1. Characteristics of study sample: Detailed investigation $\mathrm{N}=21$

\begin{tabular}{|cccc|}
\hline \multirow{2}{*}{ Characteristic } & N & $\%$ \\
& Male & 6 & $29 \%$ \\
\cline { 2 - 4 } & Female & 15 & $71 \%$ \\
\hline Partnership & Worked alone & 11 & $52 \%$ \\
& With a partner & 10 & $48 \%$ \\
\cline { 2 - 4 } & Project at fair & 20 & $95 \%$ \\
\hline \multirow{2}{*}{$\begin{array}{c}\text { Completion of } \\
\text { program }\end{array}$} & Incomplete project & 1 & $5 \%$ \\
\hline Project Type & Science Inquiry & 13 & $62 \%$ \\
\cline { 2 - 4 } & Engineering Design & 8 & $36 \%$ \\
\hline
\end{tabular}

\section{Treatment}

For the purposes of this mixed-methods evaluation, it was intended that all participants were offered the same opportunities characteristic of a fully supported science fair experience. Through the science fair program, students took part in informal weekly meetings to discuss progress, were offered access to knowledgeable mentors, materials and necessary equipment, were provided motivational support, and given guidelines including informational packets and deadlines associated with successful completion of their inquiry-based project. The fair director and I acted as "coaches" of the inquiry process, as well as researchers for this study, documenting student's progress and providing anonymous surveys and interview opportunities to gather feedback. 
Instruments

Pre-registration surveys. An online form was created to gather basic information including names, proposed topic ideas, and whether the student intended to work with a partner. Students also provided information regarding their primary science teacher and class period which was used to schedule their weekly appointment times (Appendix A).

Semi-structured interviews/advising meetings. One of the key aspects of program coaching was weekly one-on-one meetings with participants. Each student was assigned a five minute meeting time during one of their science classes for the term. The designated meeting time allowed them the opportunity to discuss any questions they had, give me or the program director an update on their progress, and discuss challenges or barriers they may have been facing in completing their project. It was my opportunity to get a better understanding of their time management skills, attitude or motivations toward their project, and what additional support, if any, they needed to stay on track with their project goals. It was my intention to touch on key barriers students were facing at the time of the meeting, and what mitigation we as a coaching staff might offer to help them to overcome the barrier. I documented their responses to these questions in an electronic spreadsheet specifically designated for weekly meetings (example entry, Appendix B).

During weekly meetings, participants were also given appropriate forms, information packets, and were reminded of workshops or lunch time seminars available. These meetings were our primary contact with students during school hours, and were supplemented by emails and correspondence through social media. 
Semi-Structured Exit interviews. Following the same format as utilized in Bryan \& Glynn's 2011 study, I conducted semi-structured exit interviews. All participants that consented were interviewed, either in person during their science class on their high school campus, or via submission of an online interview due to time constraints. Interviews took roughly 15-20 minutes and were documented through dictation of responses into an electronic spreadsheet. I performed all interviews, using an "interview guide" which includes an orientation and a set of questions. I developed questions after careful reading of previous studies investigating science fairs' validity in supporting IBL (Schneider \& Lumpe, 1996) and discussions with colleagues regarding the value of each question posed. In addition, flexibility in the interview structure allowed for more open discourse with the participant regarding their perceptions of science throughout their fair experience. Students that did not complete the fair process were given a slightly altered set of questions. From the original question guide, additional discussions took place prompted by student responses.

Orientation for Students:

To better understand your science fair experience, I'd like to ask you a few questions. Your answers will help us to improve the fair for next year, and we appreciate any feedback you can offer.

Question 1) What motivated you to do a science fair project this year? Question 2) What was the most challenging piece of your project and why? Question 3) What did you think of the science fair experience? Did you learn anything from it? If so what? Was it a negative experience for you? If so how? 
Question 4) Do you feel that your science fair experience helped you to better understand the way science is really done (nature of science)? Can you give an example?

For Students that did not complete the fair program:

Question 1) What motivated you to do a science fair project this year?

Question 2) What did you think of the science project experience? Did you learn anything from it? If so what? Was it a negative experience for you? If so how?

Question 3) What obstacles did you face that made you drop-out of the fair? How did this make you feel?

Question 4) Do you feel that your science fair experience helped you to better understand the way science is really done (nature of science)? Can you give an example

Skills Assessment of a participant's final project display. I assessed a sample of 18 project displays and 20 participants (some students worked in teams of two). Adhering to the (2011-2012) Oregon Department of Education Scoring guides for High School (either Science Inquiry or Engineering Design, depending on the students' research topic;

Appendix C), I awarded a score (1-6; 4 = "proficient" or meeting standards) for the categories of:

Science Inquiry -

- Forming a Question or Hypothesis

- Designing an Investigation/

- Collecting and Presenting Data

- Analyzing and Interpreting Results

Engineering Design - 
- Identifying and Defining a problem to be solved

- Generating Possible Solutions

- Testing Solutions and Collecting Data

- Analyzing and Interpreting Results

The official ODE Scoring Guides were developed by others as a response to a need for new assessment tools in alignment with the adoption of the 2009 Science Content Standards. As of 2012, Oregon state requires that a work sample of student's performance in developing these inquiry skills be evaluated using the official Scoring Guides (Fiser, 2013). As new assessment tools have not been developed for NGSS to date, I utilized the most recent tools available.

Program Assessment via an anonymous online survey. At the end of the fair process, all students, regardless of successful completion of the program, were asked to fill out an anonymous, online survey generated by Qualtrics to gather feedback on how successful the fair program was in supporting their efforts (Appendix D).Students were asked about their perceptions of all aspects of the fair process, including the types of barriers they faced as well as the usefulness of support offered. The survey was accessible for responses starting on January 1, 2014 and remained open until four weeks after the fair on March 28, 2014, to allow as many responses as possible.

\section{Procedure}


The entirety of this study was carried out at either the participants' respective high school campuses or the high school where the science fair is hosted. During the first month of school, students were introduced to the science fair through flyers, hand-outs by teachers, and presentations in their science classes by a program mentor, teacher, or a previously enrolled student. The fair program was presented to students as a way to study a topic of their personal interest that offered the possibly of scholarships and awards. All students enrolled in the Advanced Placement (AP) Statistics course of one high school were required to participate in the fair program.

Students had the opportunity to informally register for the science fair near the end of September by filling out the online pre-registration survey. All data from students was transferred into a database in order to most effectively monitor participant progress and compile contact information. Consent forms were sent home with all students that had informally registered for the fair informing them of the opportunity to take part in a research project regarding the effectiveness of our program, and were asked to return consent forms to me or the fair director during the first week of meetings.

In the weeks that followed, students attended weekly meetings with me or the fair director to discuss their research interests and were presented with information packets outlining the predicted timeline and deliverables for completing the science fair program. Meeting notes were documented by me or the fair director, and I attempted to record my observations and insights without bias or judgment regarding the student's efforts. Students were encouraged to start a logbook to track their own progress. Students were asked to report on progress of different components of their project, including their 
background research, draft research proposal, experimental design, and appropriate forms necessary for experimentation according to rules associated with an ISEF-affiliated fair.

During this time, students unable to continue with the program dropped out of the fair process by informing a coach or teacher of their desire to quit. Once removed from the program, student information was transferred from "Active" to "Withdrawn" status in the database. Just prior to winter break, in early December, official registration took place whereby students input their intended research title and category to the online registration site for the regional fair. At this point, students were required to have a finalized research proposal including background information, experimental design, materials, and risk assessment, in order to proceed with the fair process. I generated an informal end-of-term teacher's report based on each student's progress, and sent it to all respective science teachers with students participating in the fair.

Over winter break, and throughout the month of January, students finalized research plans, performed experiments, and throughout this process coaches advised them on appropriate data collection and analysis techniques. Weekly meetings, e-mails, and hand-outs acted as support throughout the experimentation process. Roughly 3-4 weeks before the fair, lunch-time seminars were offered to students as mini-workshops on topics such as data analysis, display design and content, and abstract writing. Two weeks prior to the fair, students were required to attend one of two "Mock Symposiums" in which they presented their work to science teachers acting as judges. They were given feedback from "judges", primarily regarding data analysis and presentation improvement. The fair itself spanned three days (February 26-28); the first evening the students set-up their 
display boards at the host high school, the second day the students were judged by professionals in their respective category, and the final day the students presented their work to the public, followed by a keynote speaker and an awards ceremony.

On the evening of judging day, images of all project displays were taken by a colleague in order to perform a Skills Assessment on projects chosen for the profiles. I documented scores and feedback on designated worksheets for further analysis and comparison. Upon completion of the fair, I sent email reminders to students to participate in the anonymous Program Assessment. I utilized coding schemes to analyze open-ended qualitative responses (Saldana, 2013; Trochim, 2006 ). After coding, I analyzed data from the anonymous survey for descriptive statistics using Microsoft Excel data analysis tools.

I contacted students involved in the in-depth analysis via emails to setup exit interviews. Many students that were participating in the study placed in their category for the regional fair and were preparing to compete in the state-level science fair, so interviews were postponed and in some cases responses were submitted via an online form. Responses from exit interview questions were used as a component of the profiles examining the influence of the science fair program on individual participants' understanding of science inquiry. In addition, response quotations were used to support findings from the quantitative data collected in the Program Assessment. Coding schemes were utilized to analyze open-ended responses. 


\section{Chapter 4}

\section{Results}

In order to most cohesively present data collected for the purposes of this program evaluation, the results below are organized with respect to specific questions posed including student motivation to participate, support offered by the fair program, barriers faced by participants, and possible benefits of IBL associated with the fair experience. I developed profiles of three participants in the fair as a way to examine links between support offered by the program and acquired benefits of IBL, and to illustrate findings from the larger population of students.

\section{Student motivation for participation}

As I have identified, one of the key components to our science fair program is the student and their role as a participant (Figure 1). I examined a student's initial motivation to participate in the program, collecting data from both the anonymous Program Assessment as well as interview responses. When examining responses of the anonymous Program Assessment, I found that students were primarily motivated by the prospect of strengthening their college applications (33\%) and the excitement of developing their own idea $(29 \%) .21 \%$ of respondents expressed their interest in participating based on their belief that the process would be fun. The proportion of students with intrinsic and extrinsic motivations was very similar (54\% and 46\%, respectively) and no respondents participated based on their parent's request (Table 2). 
Table 2. Students' motivation for participating in the science fair program; according to Program Assessment N=70

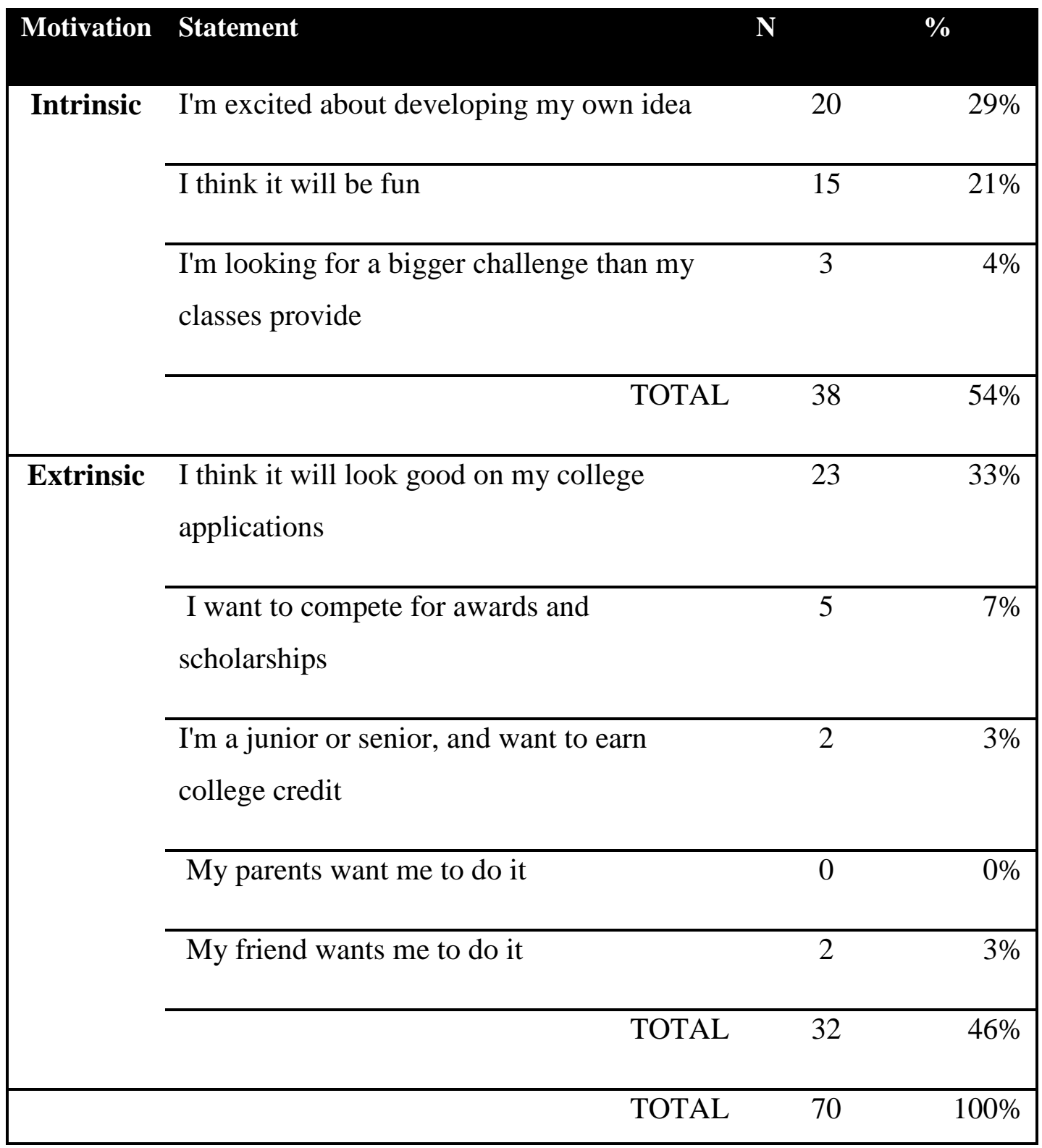

When asked about a student's motivation for participating in the science fair during exit interviews, the preponderance of answers centered on learning about a topic of their interest. A $9^{\text {th }}$ grader with science fair experience from middle school stated that 
"[my motivation for participating was] mainly the idea that I could research something I was really interested in." Another prevalent motivation by those participating in the study was the possibility to create new knowledge, or identify a problem to be solved. Several students expressed a desire to "make a difference" or "create something of relevance in the field of science." In addition, students recognized the value of participation on college applications, and a few students mentioned peer or teacher support as a motivating factor.

\section{Students' perception of support offered by program}

In order to determine student's perception of support offered by the program, several questions were posed in the Program Assessment and interview process. Questions addressed the key components of our program support, including reflective discourse, contextual knowledge from teachers and/or coaches, access to resources, motivational support, and guidelines for the process.

\section{Reflective discourse. Four different questions within the Program Assessment} were identified as relevant in addressing whether students felt that they had the opportunity to engage in reflective discourse throughout the fair process (Table 3 ). As the primary method of communication with coaches, "informal discussions during meetings" were found "very helpful" or "helpful in combination [with other support]" by $83 \%$ of survey respondents. In addition, $67 \%$ of students found "emails/phone call/text messages" a helpful form of communication. $49 \%$ of respondents to the anonymous survey did not find the program social media pages helpful, and $33 \%$ found it only 
"somewhat helpful." When asked why they did not find it helpful, many students claimed that they did not use the social media tool, or found the information redundant and unnecessary.

Table 3. Students' perception of opportunities for reflective discourse according to Program Assessment; $\mathrm{N}=70$

\begin{tabular}{|c|c|c|c|c|c|c|}
\hline \multirow{2}{*}{$\begin{array}{l}\text { Opportunities for } \\
\text { Reflective Discourse }\end{array}$} & \multicolumn{5}{|c|}{$\begin{array}{l}\text { Helpfulness of support; Frequency } \\
\qquad(\mathrm{N}) / \text { Percentage }(\%)\end{array}$} & \multirow[b]{2}{*}{ Total } \\
\hline & & $\begin{array}{c}\text { not } \\
\text { helpful/did } \\
\text { not use }\end{array}$ & $\begin{array}{l}\text { somewhat } \\
\text { helpful }\end{array}$ & $\begin{array}{l}\text { helpful in } \\
\text { combination }\end{array}$ & $\begin{array}{l}\text { very } \\
\text { helpful }\end{array}$ & \\
\hline \multirow{2}{*}{$\begin{array}{r}\text { Informal } \\
\text { discussions during } \\
\text { meetings }\end{array}$} & $\mathrm{N}$ & 4 & 8 & 34 & 24 & --- \\
\hline & $\%$ & $6 \%$ & $11 \%$ & $49 \%$ & $34 \%$ & $100 \%$ \\
\hline \multirow{2}{*}{$\begin{array}{r}\text { Emails/phone } \\
\text { calls/text messages }\end{array}$} & $\mathrm{N}$ & 6 & 17 & 22 & 25 & --- \\
\hline & $\%$ & $9 \%$ & $24 \%$ & $31 \%$ & $36 \%$ & $100 \%$ \\
\hline \multirow{2}{*}{$\begin{array}{r}\text { Social } \\
\text { media/Program } \\
\text { site }^{*}\end{array}$} & $\mathrm{~N}$ & 34 & 23 & 11 & 2 & --- \\
\hline & $\%$ & $49 \%$ & $33 \%$ & $16 \%$ & $3 \%$ & $100 \%$ \\
\hline \multirow{2}{*}{$\begin{array}{r}\text { Support with } \\
\text { judging/presenting } \\
(\text { Mock })\end{array}$} & $\mathrm{N}$ & 7 & 15 & 20 & 28 & --- \\
\hline & $\%$ & $10 \%$ & $21 \%$ & $29 \%$ & $40 \%$ & $100 \%$ \\
\hline
\end{tabular}

*Wording altered to exclude social media company name

Responses from the Program Assessment suggest that students found access to opportunities for reflective discourse helpful, which is supported by responses to open- 
ended survey questions. When asked whether the program coaches established a positive environment to explore ideas, several students mentioned opportunities in which positive, constructive exchanges took place.

" [Coaches] let us give ideas at the beginning of meetings and then helped us grow the ideas into actual projects."

"They helped my partner and I enormously with helping developing our ideas which just needed some refining."

"[Coaches supported us] by offering help but leaving enough to us so that we weren't dependent on them for our research to progress."

"My ISEF mentors [coaches] were very helpful throughout the process so I could understand my project better and realize where I was going with it when I was lost."

"[My coaches] gave feedback on ideas and helped shape my project."

Informal dialogue also took place after completion of each student's science fair project through practice judging at the Mock Symposium. 90\% of students found support with judging or presenting their presentation at least "somewhat helpful."

Support from knowledgeable teachers/mentors/coaches. In order to take part in reflective discourse regarding their science fair projects, students relied on access to knowledgeable teachers and mentors that could offer expertise. Such expertise included contextual knowledge of the student's research topic as well as knowledge regarding the inquiry process such as a familiarity with designing an experiment or analyzing and interpreting results. Questions within the Program Assessment addressed the helpfulness 
of "connecting to mentors/adult sponsors/teachers", and "help with research plan/experimental design" (Table 4).

Table 4. Student responses regarding support offered from knowledgeable mentors/teachers according to Program Assessment N=70

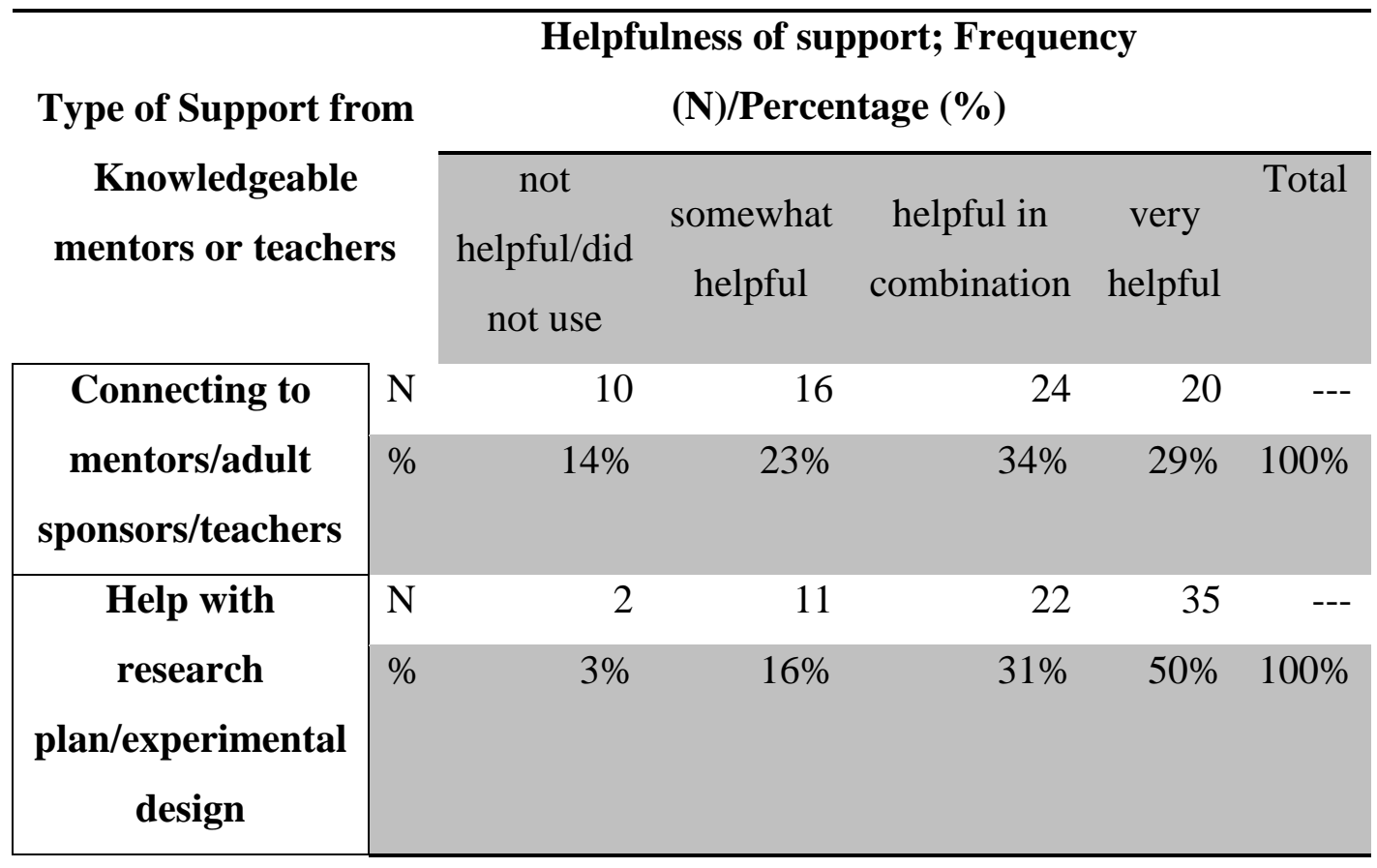

$50 \%$ of survey respondents found assistance with developing ideas associated with their research design "very helpful", and $97 \%$ of students found this support at least “somewhat helpful." $86 \%$ of survey respondents found "connections to mentors..." at least "somewhat helpful." Open-ended responses within the Program Assessment supplied additional evidence that the majority of students felt supported by the program's coaches. One student directly stated that "[they] found good connections to resources and 
other mentors specifically related to [their] research questions" from the program coaches.

Although the majority of students $(86 \%)$ responded positively regarding the helpfulness of connections with mentors or teachers, several students noted that they did not utilize support in this area rather than a lack of helpfulness. Some thought they were not offered the opportunity to connect with a mentor, or did not receive any help from their adult sponsors or teachers.

Access to Resources. Students' perceptions of the accessibility and helpfulness of resources were evaluated using Program Assessment responses (Table 5). 71\% of survey respondents found assistance in gathering resources and materials to be "helpful in combination" or "very helpful." All students that responded "not helpful/did not use" described themselves as "self-reliant" or not in need of help with gathering materials.

A large proportion of respondents $(50 \%)$ did not know that a research grant was available to them, and did not receive it. 
Table 5. Students' perceptions of "Access to Resources" according to Program Assessment

\begin{tabular}{|c|c|c|c|c|c|c|}
\hline \multirow[b]{2}{*}{ Access to Resource } & \multicolumn{6}{|c|}{$\begin{array}{l}\text { Helpfulness of support; Frequency } \\
\text { (N)/Percentage }(\%)\end{array}$} \\
\hline & & $\begin{array}{c}\text { not } \\
\text { helpful/did } \\
\text { not use }\end{array}$ & $\begin{array}{c}\text { somewhat } \\
\text { helpful }\end{array}$ & $\begin{array}{l}\text { helpful in } \\
\text { combination }\end{array}$ & $\begin{array}{c}\text { very } \\
\text { helpful }\end{array}$ & Total \\
\hline \multirow{2}{*}{$\begin{array}{l}\text { Gathering } \\
\text { resources/materials }\end{array}$} & $\mathrm{N}$ & 6 & 14 & 28 & 22 & --- \\
\hline & $\%$ & $9 \%$ & $20 \%$ & $40 \%$ & $31 \%$ & $100 \%$ \\
\hline \multirow{2}{*}{ Research Grant } & $\mathrm{N}$ & 35 & 7 & 14 & 14 & --- \\
\hline & $\%$ & $50 \%$ & $10 \%$ & $20 \%$ & $20 \%$ & $100 \%$ \\
\hline
\end{tabular}

Motivational support that fosters science self-concept. The presence of motivational support for the purpose of fostering science self-concept was investigated through responses to open-ended Program Assessment questions and interview responses. A coding scheme was developed to identify phrases relating to motivation or encouragement provided by program coaches. A question posed in the Program Assessment addressed whether students felt program coaches established a positive environment to explore ideas. In addition, responses pertaining to facilitation or improvement of a student's science self-concept were identified (Table 6). 
Table 6. Key words/phrases used to search for motivational support" responses from students

\begin{tabular}{|l|}
\hline Phrase or key word used to identify responses \\
\hline motivation, motivated \\
\hline encouragement, encouraged, reassuring \\
\hline my ideas, my interests, feedback \\
\hline
\end{tabular}

Themes that emerged when examining participant responses included: encouragement by coaches to pursue their own ideas, and reassurance by coaches of student's capabilities in science. Students felt encouraged to follow-through with their project despite setbacks because of support offered by coaches. One student noted that “[they] had almost no boundaries on our ideas and everyone's idea was supported fully by our [coaches]." Other students mentioned being motivated by "supporting and reassuring email", and "great feedback and ideas." In one case, a student described the coaching environment as a place that "encouraged and helped to renew our interest and enthusiasm in the project." Several students described reassurance from coaches that helped them to feel more confident in their science capabilities.

"meeting every week helped me to motivate myself to explore ideas."

"My original motivation was increased [because of my coaches]. I'm now curious about my topic, and where I can go with it, instead of not caring and just trying to complete a project."

"Yes, I was always helped along with my ideas and was never put down" 
Guidelines/structure of inquiry. The perceived helpfulness of guidelines for a completed inquiry project, including deadlines, information packets, and help with time management were explored through questions in the anonymous Program Assessment (Table 7). 93\% of respondents found timelines with explicit deadlines at least "somewhat helpful", and $47 \%$ of those found them "very helpful." All students found "help with forms", required to compete in the ISEF-affiliated fair, at least "somewhat helpful." Handouts and support documents, including information packets given to students outlining the inquiry process, were found "very helpful" by $40 \%$ of respondents, and at least "somewhat helpful" by $91 \%$.

Table 7. Students' perceptions of helpfulness of "guidelines/structure" according to Program Assessment

\section{Helpfulness of support; Frequency \\ $(\mathbf{N}) /$ Percentage $(\%)$}

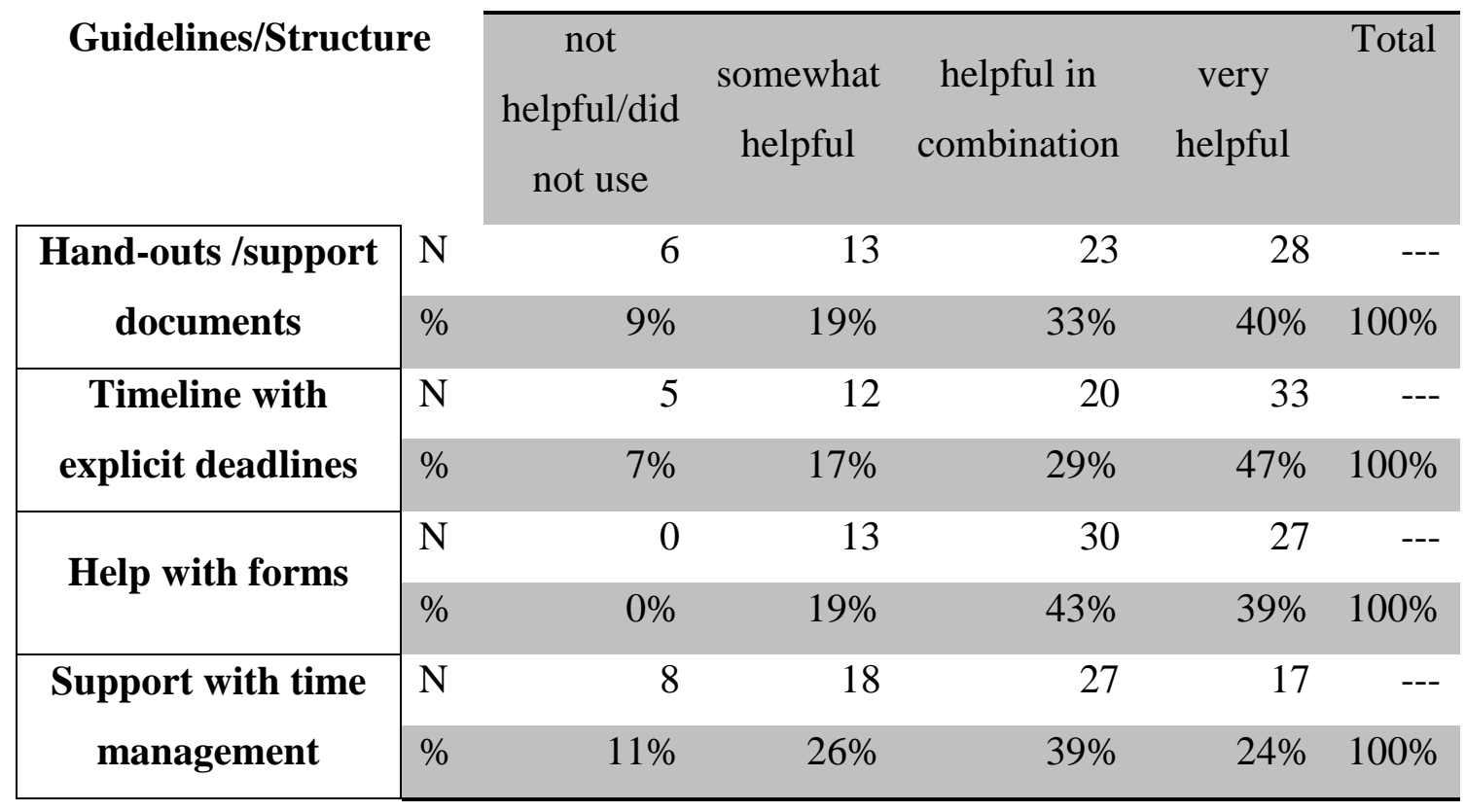


Additional support suggested by respondents. In addition to specific questions regarding components of support offered by the fair, respondents were asked to suggest other types of support they might benefit from personally. A coding scheme was applied to responses to identify support categories (Table 8). The majority of support categories identified by students were consistent with previously identified support offered by the program. 
Table 8. Coding scheme for "Additional support" suggested by Program assessment respondents

\begin{tabular}{|ll|}
\hline Category & Example(s) \\
\hline knowe/no change needed/don't & "Perfect the way it is"; "No ideas come to mind" \\
\hline More time with program coaches & "Maybe more time with [coaches] over the weekend \\
& $\begin{array}{l}\text { for people with busy weekday schedules"; "final } \\
\text { look over of your project with your [coach]" }\end{array}$ \\
\hline Guidelines/Structure & $\begin{array}{l}\text { "Make a schedule that is posted outside of the ISEF } \\
\text { doors. Make sure there are specific deadlines that } \\
\text { need to be checked off. More time management" }\end{array}$ \\
\hline Connection to outside mentors & "have better ways for people to get mentors or \\
connect with professional scientist in their field to \\
get help" \\
\hline Opportunities for Reflective & "I wish there was a website where we could go and \\
talk to other ISEFers to discuss our \\
projects/problems/questions. Like a forum"; "More \\
challenging judges at the mock symposium"
\end{tabular}


$43 \%$ of students suggested no change, either having no suggestion or saying the program was fine "as is." Of the different types of support suggested, additional guidelines or structure was dominant (23\%). Primarily, students asked for stricter deadlines and help associated with time management. $21 \%$ of students described a need for more knowledgeable mentors $(11 \%)$ or more time with their program coaches to develop their ideas (10\%). Students also acknowledge potential room for improvement in support offered by teachers and school administrators (6\%), more opportunities for reflective discourse with peers and judges (4\%) nd more access to resources, specifically funding (3\%) (Figure 3).

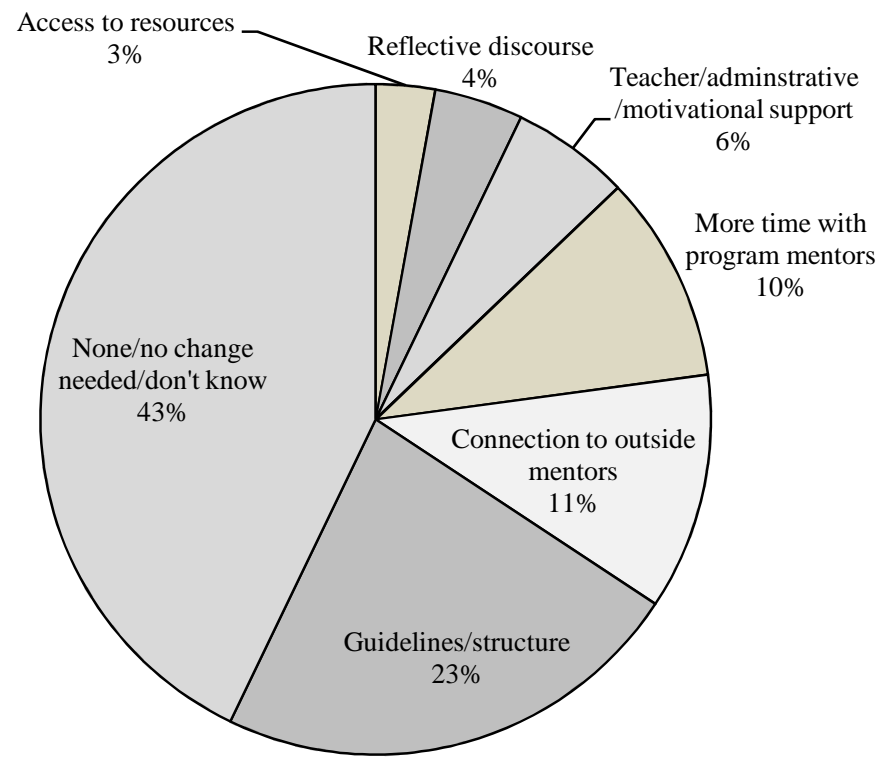

Figure 3. Program Assessment respondents' suggestions for additional support, by category 


\section{Barriers/challenges}

Data was collected regarding specific challenges that students faced during their science fair experience through Program Assessment (Table 9) and Interview responses. Students were selected to identify all the barriers they faced, as well as describing their most challenging barrier. The predominant barrier faced by survey respondents was an issue with "time management" $(69 \%)$. In an open-ended response to their "most difficult barrier", students described starting "too late" and rushing to complete their projects just prior to the fair. They also mentioned a need to put schoolwork before their extracurricular projects, and having trouble balancing time. $49 \%$ of respondents mentioned a "conflict with other extracurricular activities" as a barrier they faced. In addition, $31 \%$ of students had difficulties in completing key components of their project, such as writing their research plan. $25 \%$ or respondents found a "lack of resources" challenging in completing their science fair project. Cumulatively, $34 \%$ of students claimed a "lack of support" from either facilitators of the program (coaches/teachers) or family and friends. For 13 of the 70 students, a loss of interest or motivation contributed to challenges they faced (18\%). For students that identified "Other" as a barrier, the primary challenge described was issues with partner communication or equitable separation of responsibilities between partners (17\%). $13 \%$ of students said one of the barriers they faced was a lack of support from teachers, primarily associated with a lack of assistance in gathering resources. 
Table 9. Barriers identified by students according to Program Assessment; N=70

\begin{tabular}{|llc|}
\hline \multicolumn{1}{|c}{ Type of Barrier } & N & $\%$ \\
\hline Time management & 49 & $69 \%$ \\
\hline $\begin{array}{l}\text { Difficulty in completing key components (research } \\
\text { plan, experiment, analysis) }\end{array}$ & 22 & $31 \%$ \\
\hline Lack of support from coaches & 3 & $4 \%$ \\
\hline Lack of support from teacher(s) & 9 & $13 \%$ \\
\hline Lack of support from parents/extended family & 4 & $6 \%$ \\
\hline Lack of support/encouragement from peers & 5 & $7 \%$ \\
\hline Lack of resources available & 18 & $25 \%$ \\
\hline Conflicted with other extracurricular activity & 35 & $49 \%$ \\
\hline Partner dropped out & 3 & $4 \%$ \\
\hline Lack of interest/didn't stay engaged in project & 13 & $18 \%$ \\
\hline Other or None & 12 & $17 \%$ \\
\hline
\end{tabular}

When asked about their greatest challenges throughout the science fair process, interview respondents had similar experiences. Many students described issues with key components of their project, specifically taking the time for background research or “finding information about people doing it, like articles." Many students described procedural challenges, specifically with carrying out new techniques and managing setbacks when things didn't go as planned. Others found balancing time between activities and the fair difficult, and managing their time accordingly. 


\section{Project Display Assessments}

During my in-depth study of 21 participants, representing 18 projects total, I had the opportunity to individually assess each student's project display using the ODE Official Scoring Guides. I identified 12 Science Inquiry projects, and 6 Engineering Design projects to be assessed. In order to examine the potential impact of participation in the science fair program with development of inquiry skills, I examined not only overall mean scores for each category, but also the mean scores of students by grade level as well as by fair experience.

\section{Science Inquiry projects $(n=12)$}

I calculated the mean scores for each category based on all participants, as well as comparing mean scores by grade (Figure 4) and relative experience with the science fair (Figure 5). On average, students engaging in Science Inquiry projects showed proficiency in "Forming a Question" (4.25) and "Analyzing/Interpreting data" (4.08). Students were able to clearly identify a testable question, and develop a hypothesis that clearly represented variables to be tested. In addition, students developed conclusions based on evidence, and identified limitations or improvements to study design.

However, students did not meet minimum proficiencies for "Designing an Investigation" (3.25) or "Collecting/Presenting data" (3.00). Students appeared to struggle with communicating their procedure clearly, excluding definitions of variables, 
controls, and steps associated with the use of specialized equipment. Data was poorly organized, in some cases lacking proper units or explanations. In many cases, the graphs or tables did not seem to clearly represent the procedure that was described, and little explanation was offered with respect to how the data was analyzed.

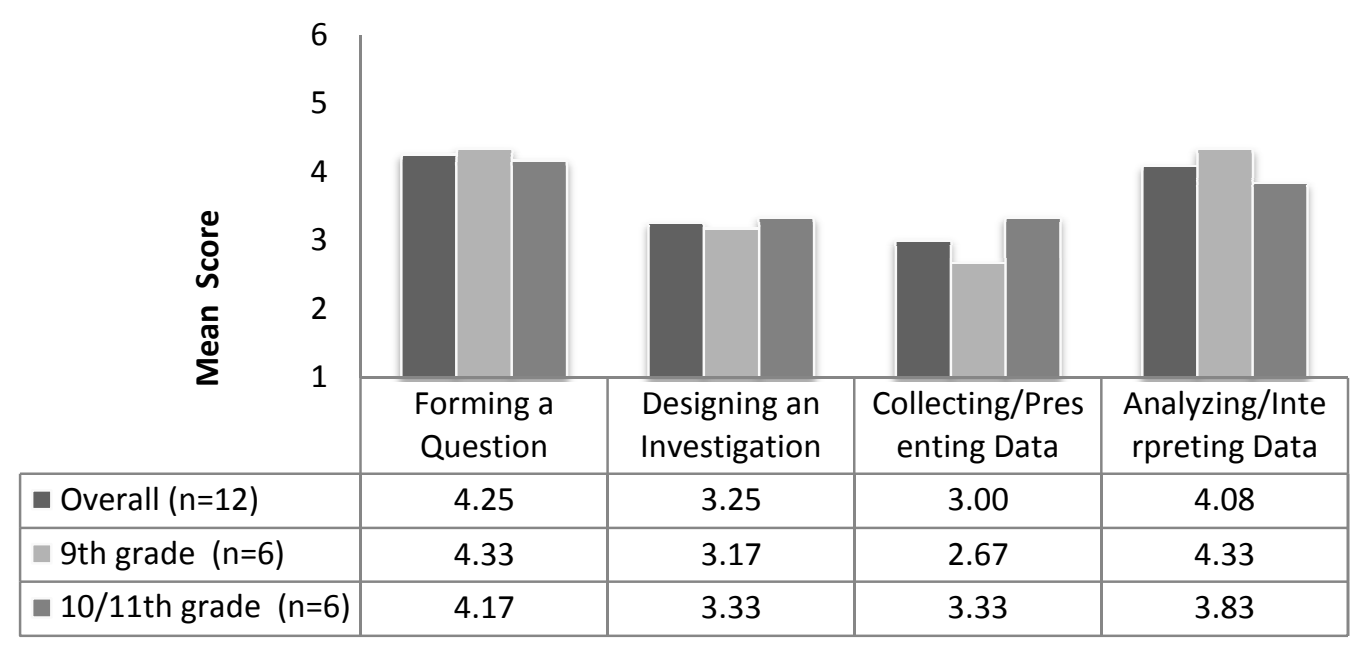

Figure 4. Comparison, by grade level, of mean Skills Assessment scores for Science Inquiry projects $\mathrm{N}=12$

When examining student scores by grade, no significant difference was found between $9^{\text {th }}$ graders and $10 / 11^{\text {th }}$ graders with at least one additional year of science coursework (unpaired t-test, $\mathrm{P}>0.05$ ). Previous fair experience did not result in a higher mean score on any category (Figure 5)( unpaired t-test, $\mathrm{P}>0.05$ ). 


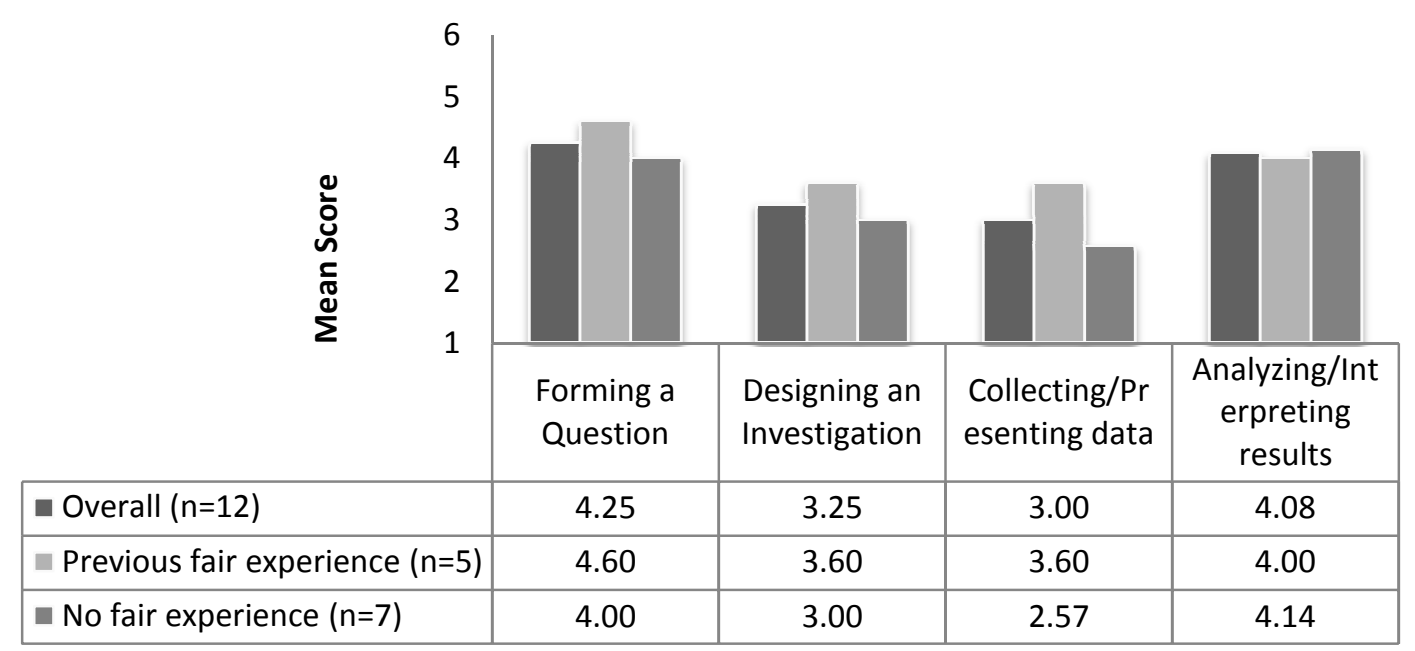

Figure 5. Comparison, by fair experience, of mean Skills Assessment scores for Science Inquiry projects $\mathrm{N}=12$

\section{Engineering Design projects $(n=6)$}

In assessing the Engineering Design project displays, I saw similar trends with respect to an average "emerging proficiency" (mean scores $\leq 3$ ). For all categories except "Defining a Problem" (mean 4.00; n=6), students appeared to struggle with fully communicating their engineering skills (Figure 6). In 4 of the 6 project displays assessed, students approached their engineering phases with a single solution, and in some cases referenced their solution incorrectly as a "hypothesis". In addition, for the majority of project displays, only anecdotal data was described, excluding any data tables or representation of trials performed, despite references to data in the results sections of each board. There was no significant difference found between students by grade level or fair experience, though these differences were represented by the same, small population (unpaired t-test, $\mathrm{P}>0.05, \mathrm{n}=6)$. 


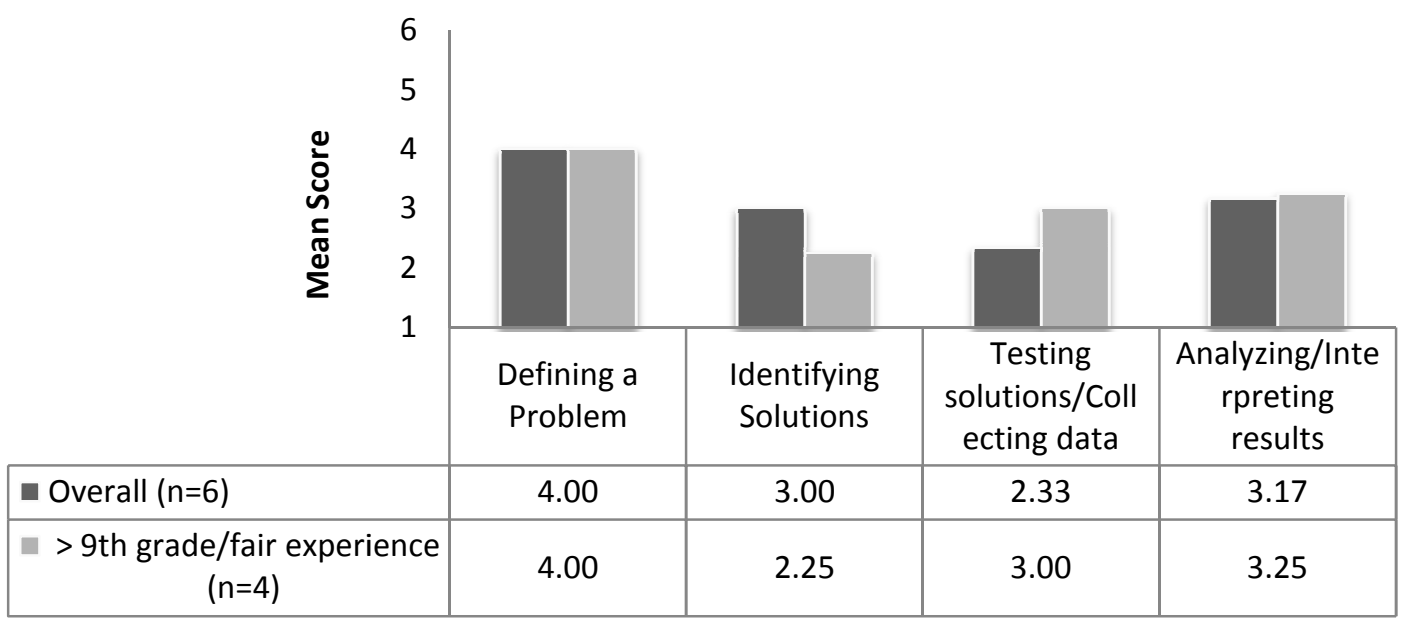

Figure 6. Comparison, by grade level/fair experience, of mean Skills Assessment scores for Engineering Design projects $\mathrm{N}=6$

Despite the appearance of higher mean scores for those students participating in

Science Inquiry projects (Figure 7), there is no statistical difference between mean scores of Science Inquiry and Engineering Design projects (unpaired t-test, $\mathrm{P}>0.05$ ). On average, all project displays that were assessed met either "emerging proficiency" or "proficiency". 


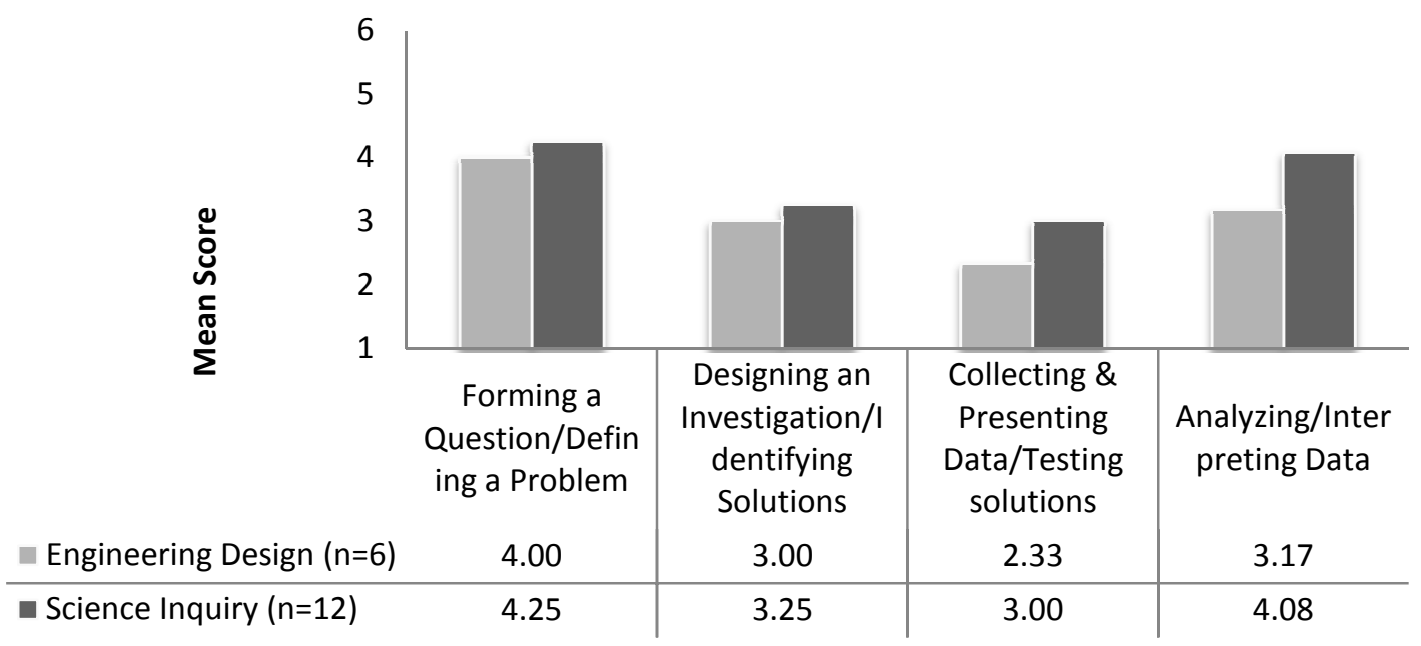

Figure 7. Comparison of mean Skills Assessment scores, Science Inquiry \& Engineering Design

Profiles: Exploring the connection between science fair program support and benefits of $I B L$

In order to examine the potential direct influence of support offered through the program on inquiry skills acquired I developed in-depth profiles of three students representing typical experiences through the science fair program. In addition to reviewing notes taken from weekly meetings and examining the student's responses to interview questions, I evaluated each student's project using the Skills Assessment in order to determine the extent to which this project display reflects support they received from the program.

In observing no difference in mean scores of participant project displays, despite grade or science fair experience, I identified three projects that represented decidedly 
different relationships between the student, the science fair program, and the achieved benefits of IBL as perceived by the student and assessed through scoring of the display. For each student, I examined their science self concept, motivation, the perceived helpfulness of support they received, how much support from the program the student utilized, the barriers they faced, and how all this translated to their ability to communicate their learned skills through their final project display.

Profile \#1: Student with strong science self-concept and inquiry skills reaffirmed through participation of the science fair program, insufficient understanding of engineering design apparent in display; limited program support utilized but found support helpful

Student. Jessica is a high school senior, and this year marked her fourth year participating in the science fair program. During her pre-registration, Jessica mentioned Biology and Anatomy \& Physiology as her favorite classes. She runs the Health \& Medicine club at school, in which doctors are invited to "come as a guest speaker once a month." In previous years, she worked with partners and her research interests centered on different behavioral studies. For her project this year, she intended to do an engineering project, focusing on a "biological engineering project geared towards the brain or the heart." Her project focused on an engineering goal to design an application for monitoring a change in spinal fluid pressure within Ventriculoperitoneal shunts. For her project, Jessica was awarded first place in her category, an award for 
"Multidisciplinary Research", and was chosen as one of three projects to represent our district at the International Science \& Engineering Fair (ISEF).

Involvement and motivation for participation. For the first month of the science fair program, Jessica was unable to attend weekly meetings because she was focusing on college applications. She checked in with program mentors occasionally to confirm her interest in the program, but was confident in her ability to successfully complete her project with limited support. She described her motivation for participating as a drive to "do something significant" during high school, and mentioned that the science fair program "presented such a wonderful opportunity to engineer something and move forward with a significant idea with immense support." Throughout the fair process, Jessica maintained her independence from the program but was dedicated to her project.

Perception of support offered. Jessica acknowledged that she did not make use of many resources provided by the program, such as information packets or emails, but spoke highly of the availability of support. Most relevant to her science fair experience was motivational support provided by program coaches.

"I believe the program itself is excellent. It felt like you and Amy were very willing to find me the help needed when facing any obstacle. It was also clear that you guys had my best interest at heart and were willing to go out of your way." 
Barriers faced during the process. As with the majority of students, Jessica's primary barrier throughout her science fair experience was time management. Her engineering project required many complex phases and she found it challenging to apply enough time to each step. In addition, she described the challenges of modeling different scientific concepts, and designing components to support engineering goals.

"Not only was it difficult to make the circuit itself, but creating a display to showcase my work required a process. For example, creating a water pump of some sort in order to test the circuit was difficult because it had to imitate spinal fluid in a brain and work every time it was tested."

Understanding of inquiry and applications of science. Jessica attributed her science fair experience to many skills and perceptions of science she did not receive in a classroom. She claimed to learn more about the "value of timely work and preparation" than in "any of [her] scheduled classes" and had the opportunity to "experience the scientific method, which high school experiments don't provide." Applications of the scientific method during her science fair experience helped her to understand that "one learns more when something that was predicted to work doesn't yield the expected results."

Jessica was also able to make direct connections between classroom content, such as electricity and circuitry, that she could "put into practice" with this year's project. She felt that the science fair program inspired her to "know the material to satisfy the longterm goal of creating [her] own functional circuit, as opposed to generally knowing the 
material for a test [in a classroom]." Jessica was able to utilize scientific concepts like Ohm's law, the function of resistors, and voltage she learned from her physics class, and reinforce her understanding through a hands-on experience.

Although a connection to the science fair experience is not explicit, Jessica appeared to have a comprehensive understanding of the nature of science. She described the complexity of science on scales from "the body's inner autonomic process, to human behavior, to the structure of the Earth itself, and finally the Earth's role in the solar system." Jessica described the nature of science as a goal to "tackle these complexities and attempt to integrate what seem to be separately complex entities into an interlaced network", touching on inherent patterns in nature and science's role to help understand them. 
Table 10. Skills Assessment of Jessica's Engineering Design project display

\begin{tabular}{|c|c|c|c|c|}
\hline & $\begin{array}{c}\text { Identifying and } \\
\text { Defining a Problem to } \\
\text { be Solved }\end{array}$ & $\begin{array}{l}\text { Generating Possible } \\
\text { Solutions }\end{array}$ & $\begin{array}{c}\text { Testing Solutions \& } \\
\text { Collecting Data }\end{array}$ & $\begin{array}{l}\text { Analyzing/Interpre } \\
\text { ting results }\end{array}$ \\
\hline 苛 & 6 & 2 & 3 & 4 \\
\hline 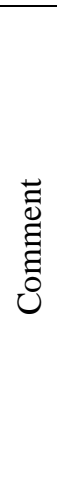 & $\begin{array}{l}\text { describes what a VP } \\
\text { shunt is, how it can } \\
\text { fail, and why } \\
\text { notification of failure is } \\
\text { important; identifies } \\
\text { problem to be solved; } \\
\text { describes criteria } \\
\text { associated with } \\
\text { resistance of spinal } \\
\text { fluid, constraints } \\
\text { associated with design } \\
\text { approach }\end{array}$ & $\begin{array}{l}\text { described only one } \\
\text { approach to solving the } \\
\text { identified problem, but } \\
\text { described phases or } \\
\text { stages and iterations } \\
\text { based on trials; treated } \\
\text { the project as science } \\
\text { inquiry rather than } \\
\text { engineering, with a } \\
\text { hypothesis (single } \\
\text { approach) }\end{array}$ & $\begin{array}{c}\text { created and } \\
\text { modified a } \\
\text { prototype, collected } \\
\text { data on multiple } \\
\text { components - } \\
\text { models/diagrams of } \\
\text { process included } \\
\text { but no data } \\
\text { tables/measurement } \\
\text { s on display just } \\
\text { observations }\end{array}$ & $\begin{array}{l}\text { used observations } \\
\text { to describe } \\
\text { strengths and } \\
\text { weaknesses of } \\
\text { design; described } \\
\text { design } \\
\text { modification and } \\
\text { future plans based } \\
\text { on into gathered }\end{array}$ \\
\hline
\end{tabular}

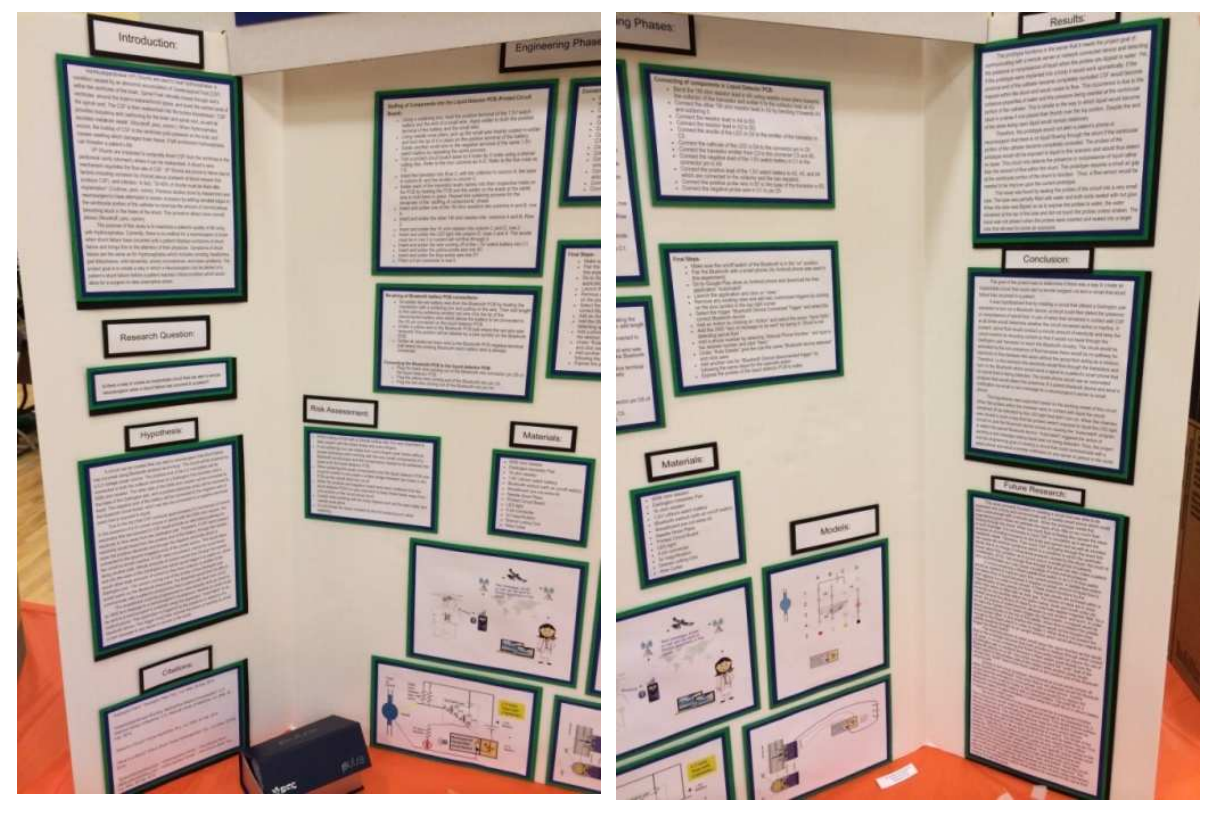

Figure 8. Images of Jessica's project display 
Skills Assessment. Jessica's project display, presented at the fair, was scored based on its alignment with requirements of an Engineering Design work sample for high school. Jessica shows a clear understanding of how to identify a problem, and present evidence that supports a design solution (Table 10). She appeared to misunderstand the structure of an engineering project, describing a single solution to her design problem, represented as a "hypothesis." Her display included models and diagrams of the prototype she developed, and she described observations that were made but no data tables or information about trials or replication for verification of functionality. Jessica's analysis of data that was provided touched on limitations and strengths of her design, and future plans for improvement. Overall, her display did not display proficiency in engineering design skills as defined by the DOE scoring guide.

Jessica's past experiences with the fair program, or understanding of inquiry from the classroom, enabled her to successfully complete her science fair project with limited support. She was confident in her abilities as a science-minded person, and could clearly describe the complex nature of science. However, she did not seem to have a clear understanding of requirements for completion of a successful engineering project, and did not identify multiple solutions to her design problem. She seemed to have a clear understanding of the structure of a science inquiry project, but did not make a distinction between inquiry and engineering project structures. This is an example of potentially greater need from the science fair program for support in understanding engineering design. 
Profile \#2: Student with poor science self-concept, and basic inquiry skills with difficulties in utilizing program support; limited benefits of inquiry

Student. Abby is a high school sophomore, and this year was her first time completing a science fair project. She enrolled in the program last year, but did not complete it. Over the summer, she took a workshop series I hosted regarding key aspects of the science fair process, and showed a renewed interest in the program. During her pre-registration, Abby mentioned interests in writing, bike-riding, hiking, art, and environmental science. For her project this year, she and a partner were interested in exploring the relationship between memory and music, specifically looking at either "musical therapy for degenerative diseases" or other benefits to playing music. Her final project examined the relationship between brain plasticity and musicianship. Abby's project did not win any awards or recognitions as a product of the judging process.

Involvement and motivation for participation. From the beginning of her fair experience, Abby exhibited tendencies of self-doubt and anxiety. In weekly meetings, she discussed issues with communicating with her partner, and "was really anxious about deciding on a topic, and understanding what it takes to do any experiment." After not being able to "follow through" with her project last year, she "really felt like [she] should do, and of course, wanted to do" a project this year. She wanted to add the fair program to her list of "things I've tried" and considered it a challenge worth exploring. Throughout the fair process, Abby struggled with feeling confident in her ability to make decisions and found the more student-directed nature of the process very challenging. In 
one specific entry I made from our weekly meetings, I took note of her need for additional support:

"Concerned that they are not far enough in progress. Needs help with reviewing RPA[Research plan] and giving reassurance. Left comments on RPA [research plan] and chatted with [Abby] about what needs to be completed to get approval (on g-chat 11/21 night). She is anxious! But I think she is feeling better. She just needs reassurance :)"

Abby met with me shortly before official registration, the cut-off date to withdraw from the program, feeling insecure about their progress. I noted that she was "incredibly anxious and concerned about deadlines, and feeling overwhelmed. I reassured her that she is doing a great job, and I am proud of their thoughtfulness in the process." She decided to continue the project, but continued to be anxious about her performance and competence throughout the program.

Perception of Support offered. Unlike Jessica, Abby was present for every weekly meeting and came prepared with specific questions and her logbook. Despite her attendance, she wasn't sure "how to utilize them effectively, and ended up communicating better through email." She contacted her program coaches frequently through emails and scheduled additional meetings when necessary. She recommended additional structure to meeting times or progress reports, like a "physical list of 'things I've completed' and 'objectives'." 
Abby found the "guidance packets and many sheets very self-standing, organized and helpful." They gave her the information necessary for her to maintain a "balance between the individual's work and creating the unique idea, and having the help of adult guidance/mentoring." She understood that the program was intended to facilitate a learning experience, but did not offer strict deadlines or grades as in the classroom.

"For me, this program pretty much relied on the student to be selfsufficient and set their own deadlines and pace with no rigid demands. (Which I somewhat liked, but also disliked the freedom... I have problems when something doesn't have a due date with a "late" penalty.)"

Abby was very grateful for motivational support offered by coaches throughout the process. In describing the helpfulness of support offered by her program coach, she had this to say:

"I cannot thank you enough for all that you have given us--- you've really transformed our very-general-idea-of-a-project in two paragraphs...into an entire potential experiment!-- or a detailed scaffolding of one. You have provided us with a clear path to do what's next (completing that research plan), clarified and answered our confusions and questions, and snuffed my concerns of falling behind. Thank you, thank you, thank you. I have a true understanding of what a project would look like now, and I am excited! We have so much to do!"

Barriers faced during the process. Abby identified her greatest challenge as management of time, between school work, the project, and effectively using time with her partner. She found it difficult to balance responsibilities of school work in addition to 
extracurricular activities. Communication with her partner was also a challenge. Specifically, working with a partner led to "creative differences" and inconsistent levels of communication. In addition, they were not "always on the same track of knowing what the other person was doing." For Abby, she found it difficult to make decisions about the project, and her partner was not as anxious about decisions that were made. This resulted in delays to the project, and added stress to Abby.

Understanding of inquiry and applications of science. For Abby, the science fair experience gave her the opportunity to feel more confident in her problem-solving and communication skills. She approached the fair with anxiety that she would not be able to complete the program again, but through her experience she was "really happy, and almost proud of [her]self, and [her] partner, that [they] could follow through with it and complete a project." Despite not winning any awards, she felt it was accomplishment in itself to finish because they "really went through some hard times, and challenges" which they overcame.

"I learned a lot of valuable skills in understanding and communicating with people, and what working together in a group project (creating ideas together, organizing, and communicating) really means, that I can certainly use for future reference."

In addition to supporting her communication and problem-solving skills, Abby saw the science fair program as a way to observe "how science can be applicable in the 'real world' outside the classroom." Although she conducted a behavioral study that was 
unrelated to content in her Chemistry class, Abby stated that "in a way doing a project brings more meaning and purpose, and enthusiasm to "why we are learning these things in class'. What I mean is, it's maybe not 'better understanding what I learned in my science class' but see the bigger picture of science'." In describing her understanding of science in general, Abby acknowledged that the fair itself helped to reconfirm her views on the "broad range of knowledge ... that science encompasses."

"Science is about exploration, discovery, and questioning about the world, and why things are the way they are. How the world works... I suppose that the final moment when we got to see other people's projects was the most interesting because there were people there that I didn't even know were into science, or doing a science project-- but they were pursuing what they were interested in."

Skills Assessment. Abby did an outstanding job of forming a testable question backed by extensive background knowledge. Her description of her experiment was fairly well formed, but lacked a definition of test groups. She did a good job of describing potential patterns or trends, but her presentation of data was difficult to follow. She had described challenges with understanding the relevance and best methods to analyze qualitative data through emails and meetings. This confusion is apparent in her lack of organized data on her display. This was also represented by a lack of statistic evidence to support her findings. Despite her challenges in working with data, Abby did a sufficient job in describing her results and possible limitations to her study (Table 11). 
Table 11. Skills Assessment of Abby's Science Inquiry project display

\begin{tabular}{|c|c|c|c|c|}
\hline & $\begin{array}{l}\text { Forming a } \\
\text { Question }\end{array}$ & $\begin{array}{l}\text { Designing an } \\
\text { Investigation }\end{array}$ & $\begin{array}{c}\text { Collecting/Presenting } \\
\text { data }\end{array}$ & $\begin{array}{l}\text { Analyzing/Interpreting } \\
\text { results }\end{array}$ \\
\hline 苛 & 6 & 4 & 3 & 4 \\
\hline 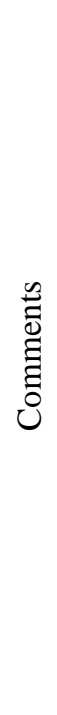 & $\begin{array}{l}\text { question is } \\
\text { specific, } \\
\text { identifying } \\
\text { variable/factors; } \\
\text { hypothesis very } \\
\text { specific, great } \\
\text { guide to expt } \\
\text { design, } \\
\text { identifying test } \\
\text { groups and } \\
\text { what will be } \\
\text { tested; } \\
\text { extensive } \\
\text { background } \\
\text { information } \\
\text { pertinent to } \\
\text { study with in- } \\
\text { line citations }\end{array}$ & $\begin{array}{l}\text { procedural overview } \\
\text { thorough but does not } \\
\text { address/include survey } \\
\text { questions/factors to be } \\
\text { examined in relation to } \\
\text { identifying test groups; } \\
\text { outlines self-reported } \\
\text { score tracking and } \\
\text { brain training game; } \\
\text { touches on observing } \\
\text { trends/patterns; } \\
\text { difficult to ascertain the } \\
\text { quality/quantity of data } \\
\text { that will be acquired }\end{array}$ & $\begin{array}{l}\text { data recorded and } \\
\text { consistent with plan } \\
\text { but somewhat } \\
\text { unorganized/difficult } \\
\text { to follow; some } \\
\text { missing/confusing } \\
\text { labels }\end{array}$ & $\begin{array}{l}\text { Thorough analysis of } \\
\text { results; no statistical } \\
\text { evidence but great } \\
\text { evaluation of study } \\
\text { limitations; good } \\
\text { discussion regarding } \\
\text { future research based } \\
\text { on results }\end{array}$ \\
\hline
\end{tabular}
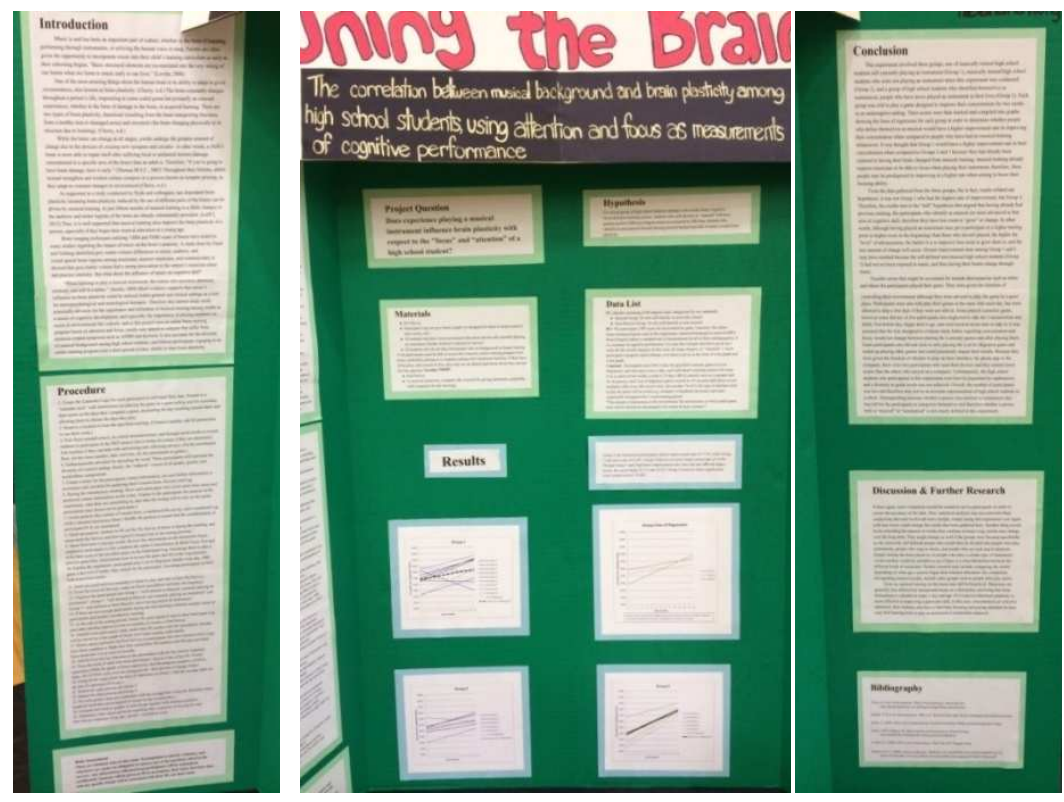

Figure 9. Images of Abby's project display 
Profile \#3. Student with low science self-concept that gained limited benefits from inquiry experience

Student. Beverly is a high school freshman $\left(9^{\text {th }}\right.$ grader $)$, and this year was her first time completing a science fair project. She self-identified as not being "a science-oriented person”. By completing the science fair program, she replaced an in-class inquiry project. During her pre-registration, Beverly identified her interests in playing softball, taking pictures, and painting her nails. For her project this year, she was interested in "creating something" and showed an immediate interest in nail polish. She also mentioned the possibility of making "something useful for cats". Her final project examined the presence of toluene in " 3 -free" nail polishes that claim to exclude toluene in their contents. At the fair, Beverly was given a "Promising Young Scientist" award in her category

Involvement and motivation for participation. Beverly entered the science fair program with a great attitude, excited for the possibility to participate in something of her own interest. Her original motivation for participating was to "learn new things" and because she considered it "a good experience." She was most interested in learning more about nail polish because she wanted to learn why "nail polish stinks" and to "do something original that barely anyone has done. Not like cancer or something like that." Although her initial motivation was to learn something new, or create something, she noted her disappointment during the judging experience in not winning more awards. 
Perception of Support offered. Throughout the entirety of the fair program, Beverly attended every meeting with her program coaches, and engaged in conversation about background information, experimental design, and the best approaches to address her research question. Within the first few weeks of the program, she had connected with an expert on chemical safety, and discussed possible tests she could conduct.

For Beverly, she would not have "done anything near what [she] did" without the program's support. She was appreciative for all the time coaches spent with her in creating her idea, and answering questions. Outside of the program coaches, Beverly did not feel supported, stating that "teachers expect us to do it on your own completely, and most parents (my parents) are not the 'helping that much' kind because they don't get it either." Beverly found feedback from peers and judges at the fair encouraging because they "learned from her topic." She made no mention of information packets, explicit timelines or resources when describing the support she received from the program, primarily focusing on motivational support and help from knowledgeable mentors.

Barriers faced during the process. In describing the challenges that she faced, Beverly identified several different barriers she encountered. She had trouble developing her project idea, and completing key components of her project like background research and experimental design. She was concerned that her approach would generate "data [that] wouldn't have the right information", expecting specific results. Beverly attempted several different measurement techniques, viewing her initial attempts as failures rather 
than understanding that a hypothesis unsupported by data can represent accurate results. As with all students, she also struggled with time management, and "finding time for school work, tests, studying, [and] hanging out with friends."

\section{Understanding of inquiry and applications of science. Despite Beverly's} enjoyment in participating in the science fair program, she did not seem to acquire benefits of IBL as with Jessica or Abby. Beverly acknowledged that she has "never been a science-oriented person" but the fair experience did give her an opportunity to make connections to class she wouldn't have made before. However, she stated that she doesn't "like science at all" and did not see the fair as an opportunity to learn about content. She did hint at the idea that science fairs give you the opportunity to apply knowledge, but described the fair itself as something separate from "science."

"Science can be really cool, like at the science fair and experiments with people, and things we do and how it effects us. But other things like atoms, and things, I never really made the connection in my mind. It's really boring."

Beverly did gain some insights into her own organizational skills and focus. She described other projects at the fair with detailed logbooks, saying that "I need to be that focused, and that I could be organized if I put my mind to it." She also seemed to harbor misconceptions about science inquiry when describing her desire to get the "right answer." Her experimental design yielded inconclusive results, and Beverly found this 
very difficult to understand. She was offered additional support through an outside facility to examine her samples using more sophisticated equipment, with similar results.

Skills Assessment. Beverly's challenges in understanding basic inquiry skills were well represented in her project display. She showed an ability to form a testable question, and gave sufficient background information, but the exact approach for testing her hypothesis was difficult to find. The method she described was incredibly limited, and she did not define variables or replication. While Beverly made an attempt to describe observations from the study, she did not include any data tables or an explanation for the absence of data. A single HPLC spectrum was attached to the board with no associated explanation or analysis. Her conclusion included incomplete explanations, and a poor connection between the original intent of her project and findings (Table 12). 
Table 12. Skills Assessment of Beverly's Science Inquiry project display

\begin{tabular}{|c|c|c|c|c|}
\hline & Forming a Question & $\begin{array}{l}\text { Designing an } \\
\text { Investigation }\end{array}$ & $\begin{array}{c}\text { Collecting/Presenting } \\
\text { data }\end{array}$ & $\begin{array}{l}\text { Analyzing/Interpreting } \\
\text { results }\end{array}$ \\
\hline 苛 & 4 & 2 & 1 & 3 \\
\hline 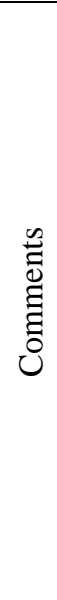 & $\begin{array}{l}\text { Question/hypothesis } \\
\text { can be tested; } \\
\text { background } \\
\text { information } \\
\text { describes typical } \\
\text { nail polish } \\
\text { components and } \\
\text { toxic properties of } \\
\text { toluene; straight- } \\
\text { forward and } \\
\text { testable, but exact } \\
\text { approach for testing } \\
\text { not as clear as it } \\
\text { could be }\end{array}$ & $\begin{array}{l}\text { method is } \\
\text { limited; } \\
\text { mentions } \\
\text { "control" but } \\
\text { does not } \\
\text { address } \\
\text { variables, } \\
\text { volumes/units; } \\
\text { unclear what } \\
\text { kind of data is } \\
\text { produced, } \\
\text { doesn't appear } \\
\text { to fully } \\
\text { understand } \\
\text { procedure. }\end{array}$ & $\begin{array}{l}\text { No data tables or } \\
\text { explanation for } \\
\text { missing data; no } \\
\text { organization of data, } \\
\text { just word } \\
\text { description. No } \\
\text { replication? } \\
\text { Spectrum from } \\
\text { HPLC analysis of } \\
\text { one compound } \\
\text { present without any } \\
\text { explanation }\end{array}$ & $\begin{array}{l}\text { Conclusion is short } \\
\text { but concise; it } \\
\text { provides overall } \\
\text { analysis of "results" } \\
\text { but without any } \\
\text { discussion as to why } \\
\text { the case; only partially } \\
\text { supported. No } \\
\text { mention of issues with } \\
\text { testing/accuracy of } \\
\text { design; incomplete } \\
\text { explanations, poor } \\
\text { connection between } \\
\text { intent and findings }\end{array}$ \\
\hline
\end{tabular}

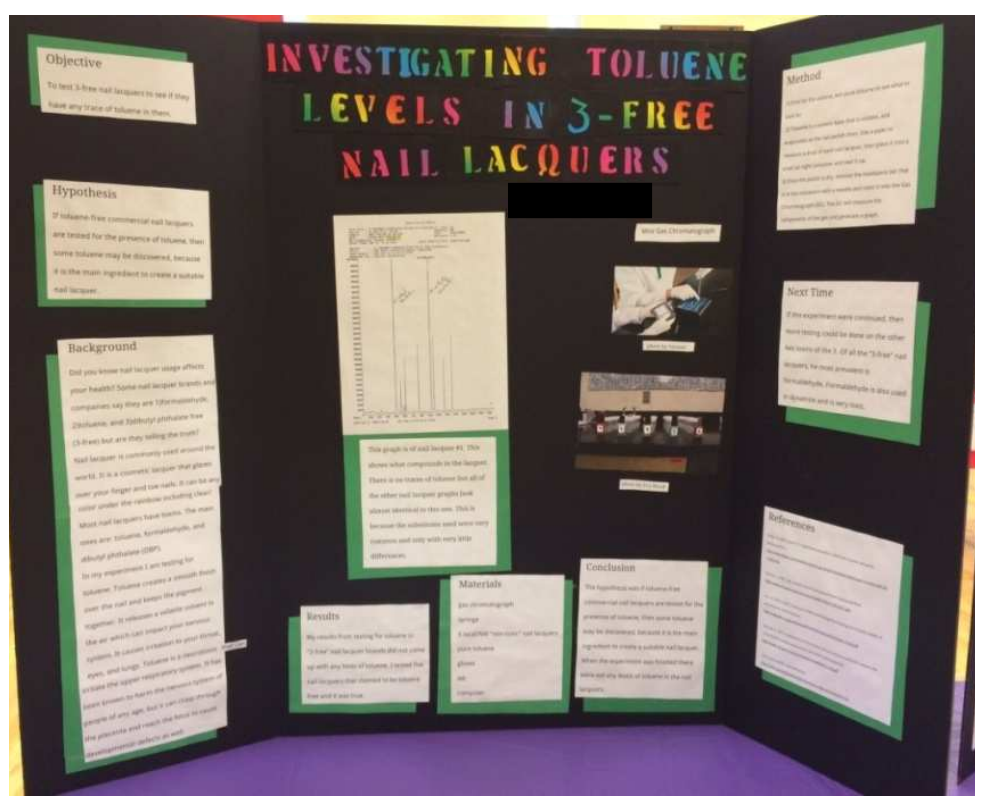

Figure 10. Image of Beverly's project display 


\section{Chapter 5}

\section{Discussion}

Evidence from a multi-faceted evaluation of the district's science fair program suggests that participants have access to an authentic inquiry based learning experience. This claim has been supported through examination of several findings, including the participant's motivation and perceived reward of participation, students' perception of support offered by the program, barriers that students face specific to this program, and benefits of IBL that students attribute to the science fair experience. Here, I would like to discuss why and how the science fair program has the potential to adequately support IBL as illustrated by these findings.

\section{Students are motivated by their own ideas or achievement (awards)}

The science fair program is presented to students as an avenue for exploration of their personal ideas as well as an opportunity to win awards or improve upon college applications. Students most likely to benefit from this program are those that seek out such opportunities. Data suggests that the primary reasons for participation included strengthening one's college applications (33\%) and developing one's own idea (29\%). Because the science fair is an extracurricular activity for the majority of participants, the experience is perceived as a personal investment which lends itself well to the necessity for student-driven learning associated with the inquiry process. Rather than approach the 
program as a teacher-directed learning experience, students understand and are welcoming of the opportunity to set the pace of their learning and define the topic they will research.

\section{Students find support offered by the program helpful}

Overwhelmingly, participants found support offered by the science fair program very helpful. Opportunities for reflective discourse through informal meetings were seen as "very helpful" or "helpful in combination" by $83 \%$ of respondents. Help with development of inquiry skills by knowledgeable mentors was perceived as at least “somewhat helpful” by $97 \%$ of survey respondents. Students spoke highly of their experiences with coaches, and the motivational support they were offered throughout the fair process. In addition, many students spoke highly of timelines and explicit deadlines (at least "somewhat helpful" 93\%), hand-outs (at least "somewhat helpful" 91\%), and support with forms (no student identified this as "not helpful"). Of the 13 different parameters that were examined for "helpfulness", only two were identified by the majority of participants as "not helpful/did not use." $49 \%$ of students did not find the social media sites associated with the fair helpful and $50 \%$ of students mentioned that they were not aware of the opportunity for a research grant. In both cases, less emphasis was given to advertising these components of the program support. 
Primary barriers do not result from a lack of support from the program but how that support was utilized

"The high school experience is characterized by an average of 5-6 hours of sleep at night, maximum. This is to ensure good grades in classes, participation in enough extracurriculars, volunteer hours, and time logged for sports and violin practice."

As stated by one of the science fair participant's above, a high school student's schedule is packed with activities inside and outside of the classroom. For many students intending to go to college, they see high school as "largely a contest" and do everything they can to fill their schedules with extracurricular activities. With this in mind, it is no surprise that the primary barrier students faced throughout their science fair program was "time management" (69\%). In addition, $49 \%$ of students found that their commitment to the science fair program was challenged by other extracurricular activities. Additional barriers that students mention can be attributed to a lack of time to invest in their project. Students noted issues with communicating or coordinating with partners (17\%) and the desire for more time with mentors after school or on weekends (10\%). Several students suggested stricter deadlines and more explicit instructions as a way to better manage their busy schedules (23\%). Although this key barrier of time management is a systemic issue, not created specifically by the science fair program, it is something that can be addressed. 
Students attribute the science fair program with development of inquiry skills and an understanding of the nature of science, and applications of science

Comments from students' exit interviews were investigated for evidence that participation in the fair resulted in benefits attributed to an IBL experience. Several trends emerged from the data with respect to participation in the fair and perceptions of science. These are presented below as a series of assertions.

Assertion 1: The science fair represents the diversity of science. One-third of students participating in post-fair interviews described the fair as an opportunity for them to broaden their perception of the definition of science, noting the diversity of projects at the fair. One student mentioned that they "look at it [science] a little differently... as a broader subject than I did before. Especially walking through the fair, I saw all the different things about science I wasn't really aware about.” Another student succinctly described the value of observing other projects, stating that "there are so many possible projects that are based around a million different science concepts that, even with the excessive amount of high schoolers participating in science fairs, cannot all be touched on." One student described the fair experience as affirmation of her understanding of the diversity of science, stating "my impression of science hasn't changed because I've always been really aware of the diversity of science, like plants and invertebrates and etc. Even within my group [life \& environmental sciences category], everyone had their own thing that I thought was really cool. Even in behavioral and electronics and engineering." 
This representation of the diversity of science also gave students a heightened perception of their peers' capabilities in science, and broadened their perspective regarding the types of people that engage in scientific research.

"the final moment when we got to see other people's projects was the most interesting because there were people there that I didn't even know were into science, or doing a science project, but they were pursuing what they were interested in."

"It [the science fair experience] helps you realize the genius of others, something I often overlook. It gives proof of the amazing intelligences and capacities of others."

Assertion 2: The science fair program gives students the opportunity to explore their ideas with support. In describing their experience with the science fair program, many students noted their original motivations to explore new ideas, and confirmed the program's ability to support their exploration. Students described the science fair program as a facilitator of investigating personal interests that would not otherwise be supported in the classroom. Below are several quotes from students supporting this assertion.

"I think every school should have this, many kids have great ideas but never get to explore them because of school and other things in life" 
"I really like the science fair program because it's for the sake of the students who really want to make their ideas real and get rewarded for their personal ideas. Without it there'd be a lot of ideas that probably wouldn't be able to come to life and be noticed. I full-on support the science fair program whether or not I continue to do [the fair] just because it encourages the scientific side of students"

"It was so great. I'm so glad that I was given the opportunity to actually watch my ideas come to life. Some people may have the ideas but not the resources but I was fortunate enough to be given both"

Several students explicitly described the science fair program as a program developed to support them in engineering something or creating new knowledge.

"I had support and it was a program that was meant just for that if previously I didn't have the resources for it"

"[I was motivated to participate in the fair by] the opportunity to be able to build something and have a purpose to build something. And to have some backup support in doing that"

"[The science fair program] was the best way in which I knew I could create something of relevance in the field of science with amazing minds to help me along the way."

Assertion 3: The science fair program gives students opportunities to learn about applications of science. One of the main goals of IBL is to give students the opportunity to engage in hands-on experiences which utilize inquiry skills (Schneider \& Lumpe, 
1996). In addition, a proposed by-product of IBL is an introduction to the applicability of different scientific concepts. The assertion that our program allows for these opportunities was supported by several students' responses.

"I think that my goal was exceed[ed]. I was able to expand my understanding of science and its applications. It is very different from learning in a class because you are teaching yourself the information at a speed you are comfortable with..."

"Participating in ISEF always helps with the science class unit based around the scientific method; learning the basics of graphing; $x$ and $y$ variables, qualitative/quantitative observations, laws, theories, etc."

"I guess I better understood fermentation from when we learned it in biology because we just learned about the specific types because we didn't go too far into detail. So it was cool to see that happening"

These students had the opportunity to apply what they learned in the classroom, and found the application of these inquiry skills helpful. The hands-on experience of their projects gave them the opportunity to go further into "detail" about the techniques introduced in class. Several students worked in a laboratory setting, either at their school or in a university setting, and attributed their new-found inquiry skills to their science fair experience.

"Beyond everything that I researched to plan my project, I learned about how a real lab actually works, and what a career in science might be like." 
"I got to do a lot of new things, like extracting the DNA of my plants and doing gel electrophoresis"

"I became more interested in chemistry and working in labs. I always thought it would be interesting to work in a lab but it ended up being a lot more fun than I thought it would be. It was something I'd never done before. It was a lot of hands on and that's what I liked about it."

Results from this evaluation strongly suggest that the science fair program offers participants the opportunity to engage in authentic IBL. It is also the case that while many students find the program components helpful, they are unable to utilize support in such a way to promote successful IBL. In examining results from the Skills Assessment, I found that on average, participants of the in-depth study did not meet "proficiency" in the categories of "Designing an Investigation" and "Collecting and Presenting data" (SI) as well as "Identifying solutions", "Testing solutions/collecting data", and "Analyzing/Interpreting results" (ED), regardless of past science fair experience, grade level, or whether they received awards or category placement at the fair itself. According to these results, it appears that despite the perceived "helpfulness" of the program and potential to support authentic IBL, students may be unable to access program support or the benefits of IBL.

In order to further examine the relationship between participants, support offered by the program, and benefits of IBL, I performed an in-depth study of three different students' fair experiences. Findings from these profiles suggest that the benefits a student 
receives from the science fair program are highly dependent on the student's prior experience with and understanding of inquiry. I identified three different key characteristics of participants that are necessary for full utilization of the program's support: science self-concept, an understanding of basic inquiry skills, and an ability to engage in reflective discourse. Each characteristic can be gained through the science fair process, but the benefits of inquiry based learning cannot be fully realized without the presence of all three.

A student must have science self-concept, confidence in their abilities or a willingness to development such confidence. Through the fair program, this can be facilitated through motivational support offered by peers, mentors, coaches and teachers. Without science self-concept, students find it difficult to choose a research topic, or feel confident in their ability to design an experiment without considerable guidance. I observed this in the case of Abby in which her anxiety toward making decisions caused unnecessary stress and setbacks. Beverly, who never considered herself "scienceoriented" did not feel capable of completing her project without the program's support. In contrast, Jessica exhibited a strong relationship with science, describing her favorite classes as science-based and hosting a medical science club at her school. Doubt in her ability to perform was not a barrier Jessica had to overcome.

A student must have a basic understanding of inquiry. Students within the district are introduced to the concept of inquiry in the classroom beginning at the primary level. 
Through the fair process, opportunities to strengthen their understanding can be facilitated through information packets, guidelines, and background research. In addition, discussions with knowledgeable coaches and teachers can help to instruct students on skills necessary to design and carry out experiments. Without a basic understanding of inquiry, students are unable to develop testable questions or develop appropriate experimental designs without extensive scaffolding. For students new to the science fair program, it is important to offer them additional support in developing these skills. Beverly did not have a strong background in inquiry. Her inability to represent these skills in her project display may have resulted from challenges in interpreting information packets geared toward students with basic inquiry experience.

A student must have the ability to engage in reflective discourse. One of the key features intended to promote successful inquiry through the science fair program is the opportunity for reflective discourse. The ability to discuss ideas, misconceptions, and questions pertaining to one's research are critical for developing a project, and reflecting on what a student has learned throughout their experience. Reflective discourse can be facilitated through informal meetings with coaches, discussion with peers, and presentation of projects to judges. However, without science self-concept and basic inquiry skills, a student would find it incredibly difficult to engage in genuine discussions regarding their research. They would find it difficult to communicate ideas in the absence of appropriate background knowledge. For Abby, one of her biggest barriers was communicating her ideas with her coaches and partner. This inability to thoughtfully 
reflect on her findings was evident in her lack of data organization or analysis on her project display.

Through an initial motivation to participate, science self-concept, basic inquiry skills, and reflective discourse, students are more likely to make connections between their science fair project and science in general, defining their experience in the fair as an application of science that can be connected to a bigger picture. Without these characteristics, it appears to be difficult for a student to satisfy their original motivations of "creating something new" or winning awards. Students may also find components of the fair helpful, but are incapable of utilizing the support that is offered. In order for the fair program to effectively promote successful IBL for the greatest number of students, characteristics that the students enter the program should be more closely examined, and more opportunities to develop these skills should be considered.

Recommendations in order to make program more accessible to all participants

Identify the stage at which a student enters the science fair program through a modified pre-registration survey to give program mentors the opportunity to provide more targeted support. It may also be worthwhile to offer slightly different guidelines or scaffolding to optimize time spent with students in developing specific skills. In addition, specialized progress reports for students that place emphasis on "development of basic 
inquiry skills" or "ability to engage in reflective discourse" would help a program coach and student to track their progress in developing necessary skills.

Develop new opportunities for students to acquire the necessary skills to benefit from program support. In order to increase the number of participants that improve their understanding of the nature of science and inquiry, more opportunities should be offered to improve upon science self-concept, basic inquiry skills, and reflective discourse.

In the case of science self-concept, it may be worthwhile to host a science showcase at the beginning of each school using the previous years' project displays. For many students, witnessing the diversity of projects and types of individuals participating in the program on fair day was inspiring. A showcase of that diversity at the beginning of the fair program would introduce students to the idea that anyone can be a "scientist" and a wide range of personal interests can be explored in the name of science.

Students that self-identify a need to develop basic inquiry skills through a modified pre-registration survey could be offered modified information packets and scaffolding for developing these skills. Currently, all students receive the same information with the intention of following the same timeline, and slight deviation is expected based on the type of project rather than the participant's skill level. In addition to modified handouts, additional workshops or seminars could be presented to students new to the fair in order introduce them to inquiry skills. 
The lack of helpfulness found in the program's social media sites represents an opening for improvement in opportunities for reflective discourse with peers. It would be worthwhile to investigate new options suggested by participants, including research study groups of similar topics, early-bird classes or after school sessions, or an additional practice symposium were students present to their peers. Different social media sites may be more actively utilized by participants, and could be seen as another option. Additional opportunities for students to reflect on their fair experience may also be a possibility for encouraging reflective discourse. One student recommended that all participants have "a time for you to see what people think about their experience. I think that more input on people's experiences, what they had trouble with, what they thought was easy, what could be improved [would be helpful]." Another student requested that I give her a copy of her interview responses for the sake of "personal growth", stating that "these questions and responses will be good for me to reflect upon if I happen to do [the fair] next year."

Create more access to research grants and financial support. Few students were aware of or utilized the research grant. $50 \%$ of respondents didn't use or know about it. Those that used it found it helpful, easing financial pressure for students and parents and reducing that barrier on their projects scope. This is one area that requires additional attention. In order to make the experience more accessible to students with limited access to financial support this should be more emphasized. For a few students, I recall conversations in which they had to put off starting their project because they couldn't afford supplies, but felt uncomfortable to talk about it with us. Offering the grant 
application as a normal part of the fair process that everyone does, and having the grant be need-based, would encourage more students to apply. In addition, it could act as a learning experience and mimic the grant application process that scientists must undergo in order to support their research. Students would have to apply for a grant and give clear justification for their research approach based on background research.

Establish more connections to outside mentors and help from teachers. Although the majority of respondents found connections to mentors helpful, comments suggest that students found it challenging to connect with mentors or teachers outside the program. For those with more sophisticated experiments that require lab space or specialized equipment, connection to a mentor can become a barrier to success. When asked for suggestions regarding additional support, $21 \%$ of respondents noted wanting more time with their program coaches, or more access to outside mentors. Students found the expertise from program coaches helpful, but did not think their need for more expertise was satisfied. One student stated "I did not have a designated mentor, and my teachers didn't help out. [The program coaches] were very helpful, but outside of them I didn't have any other ISEF affiliated help." Another described the challenges they and their partner faced without a connection to a mentor:

"It was hard to find a mentor that could give us the help we needed. We struggled with that but we did have some people helping us but they were not experts in that field so it was hard to work and learn everything on our own. The people with mentors definitely have an advantage over those who don't and it would have been really good if we could have gotten a mentor to help us." 
More support in this area is worth exploring, either through earlier access to mentors, earlier identification of the need for mentors, or more collaboration with teachers as mentors. One $11^{\text {th }}$ grade student, in her third year of the science fair program, offered her insights into support offered through mentorship connections:

"One of my suggestions for next year would be to have assigned teacher mentors. Ours wasn't really suited to us because we were multidisciplinary, [the assigned teacher] didn't really understand our project and we had to re-explain things to him. Because we worked with [our science teacher] for two years, we felt more confident working with her because she knew the project and could get things done. Having the designated teachers would be good for freshman/sophomores but maybe not for upper classmen..." 
References

Ajzen, I., \& Madden, T.J. (1986). Prediction of goal-directed behavior: Attitudes, intentions, and perceived behavior control. Journal of Experimental Social Psychology, $22,453-474$.

Akınoğlu, O. (2008). Assessment of the Inquiry-Based Project Implementation Process In Science Education Upon Students' Points of Views. International Journal of Instruction, $1(1), 1-12$.

Brickman, P., Gormally, C., Armstrong, N., and Hallar, B. (2009). Effects of inquirybased learning on student's science literacy skills and confidence. Internat. J. Schol. Teach. Learn. 3, 1-22.

Bryan, R. R., Glynn, S. M. and Kittleson, J. M. (2011). Motivation, achievement, and advanced placement intent of high school students learning science. Sci. Ed., 95: 1049_ 1065.

Czerniak, C. M. (1996). Predictors of success in a district science fair competition: An exploratory study. School Science and Mathematics, 96(1), 371-377.

Czerniak, C. M. and Lumpe, A. T. (1996). Predictors of Science Fair Participation Using the Theory of Planned Behavior. School Science and Mathematics, 96: 355-361

Driver, R. (1995). Constructivist approaches to science teaching. In L. P. Steffe \& J. Gale (Eds.),Constructivism in education (pp. 385-400). Hillsdale, NJ: Lawrence Erlbaum.

Dolan, E. L., \& Grady, J. (2010). Recognizing students' scientific reasoning: A tool for categorizing the complexity of reasoning during teaching by inquiry. Journal of Science Teacher Education, 21,31-55. 
Fiser, Timothy Paul. (2013). "Impact of Teacher Feedback on the Development of State Issued Scoring Guides for Science Inquiry and Engineering Design Performance Assessments". Dissertations and Theses. Paper 991. http://pdxscholar.library.pdx.edu/open_access_etds/991

Gardner, P., \& Gauld, C. (1990). Labwork and students' attitudes. In E. Hegarty-Hazel (Ed.), The student laboratory and the science curriculum (pp. 132-156). London: Routledge.

George, R. (2003). Growth in Students Attitudes about the Utility of Science over the Middle and High School Years: Evidence from the Longitudinal Study of American Youth. Journal of Science Education and Technology, 12(4), 439-448.

Hofstein, A. and Lunetta, V. N. (2004). The laboratory in science education: Foundations for the twenty-first century. Sci. Ed., 88: 28-54.

National Academy of Sciences - National Research Council Washington DC. (1996). National Science Education Standards. District of Columbia: National Academy Press, 2101Constitution Avenue, N.W., Box 285, Washington, DC 20055.

National Research Council. (2000). Inquiry and the National Science Education Standards: A Guide for Teaching and Learning. Washington, DC: The National Academies Press.

National Research Council (2012). A Framework forK-12 Science Education: Practices, Crosscutting Concepts, and Core Ideas. Washington, DC: The National Academies Press.

Norris, S., Phillips, L. M., \& Korpan, C. (2003). University students' interpretation of media reports of science and its relationship to background knowledge, interest, and reading difficulty. Public Understanding of Science, 12, 1-23. 
Oregon Department of Education (ODE) School District Annual Report Cards. (2013).Report Card Download - Oregon Department of Education. Retrieved July 14, 2014, from http://www.ode.state.or.us/data/reportcard/reports.aspx

Polman, J. L. (1999). Designing project-based science: Connecting learners through guided inquiry. New York: Teachers College Press.

Pyle, E. J. (1996). Influences on Science Fair Participant Research Design Selection and Success. School Science and Mathematics, 96: 400-406

Saldana, J. (2013). The Coding Manual for Qualitative Researchers $\left(2^{\text {nd }}\right.$ ed.). Los Angeles [i.e. Thousand Oaks, CA]: SAGE Publications. Retrieved from http://www.sagepub.com/upm-data/24614_01_Saldana_Ch_01.pdf

Schneider, R.M. \& Lumpe, A.T. (1996). The nature of student science fair projects in comparison to educational goals for science. Ohio Journal of Science, 96(4/5), 81-88.

Sorge, C., Newsome, H. E., Hagerty, J. J. (2000). Fun is not enough: Attitudes of hispanic middle school students toward science and scientists. Hispanic Journal of Behavioral Sciences 22: 332-345.

Syer, C. A., \& Shore, B. M. (2001). Science fairs: What are the sources of help for students and how prevalent is cheating? School Science and Mathematics, 101(4), 206220.

Tobin, K. G. (1990). Research on science laboratory activities. In pursuit of better questions and answers to improve learning. School Science and Mathematics, 90, 403418. 
Trochim, William M. (2006). The Research Methods Knowledge Base, 2nd Edition. Internet WWW page, at URL: <http://www.socialresearchmethods.net/kb/> (version current as of October 20, 2006)

Wilkinson, J. and Ward, M. (1997). A comparative study of students' and their teachers' perceptions of laboratory work in secondary schools. Research in Science Education, 27: 599-610.

Yasar, Senay; Baker, Dale. (2003). The impact of involvement in a science fair on seventh grade students. Paper presented at the Annual Meeting of the National Association for Research in Science Teaching (Philadelphia, PA, March 23-26, 2003). 


\section{Appendix A Pre-fair Survey}

\section{ISEF 2013/2014 Pre-Registration}

Thanks for your interest in ISEF! This is where you get to experiment, innovate, and learn what you want to learn. You must pre-register here to participate in ISEF, but you aren't $100 \%$ committed until official registration happens on November 5. We look forward to talking with you about your project!

If you have any questions about ISEF, please feel free to e-mail Amy Schauer at schauera@wlwv.k12.or.us .

* Required

Your name? *

If you have a partner, you'll add his/her name and contact info in a bit.

Your grade level $(9,10,11$, or 12) in Fall 2013? *

Your science teacher in Fall 2013?*

Wilsonville AP Statistics students, please select Mr. Schauer

What class period do you have this teacher? *

Your phone number? Format \#\#\#-\#\#\#-\#\#\# please. * We rarely use this, but might need to reach you with an update about your project.

Your e-mail address? * Please enter an address you actually do check; e-mail is really important in ISEF. 
What topic or idea are you thinking about for your ISEF project? * This is just a starting point - you (and your partner, if you have one) can change your minds later. Please give as much detail as you can.

What are your favorite classes or favorite things to do outside of school? * Answer for you and your partner, if you have one. School subjects, extra-curriculars, hobbies...let us know what interests you most and it will help us advise you on your ISEF project.

\section{Why do you want to do ISEF? *}

Answer for yourself - your partner's info comes next. Choose the BEST answer that fits you.

- $C$ I'm excited about developing my own idea

- $\quad$ I think it will look good on my college applications

- $\mathrm{I}$ think it will be fun

- C I want to compete for awards and scholarships

- $\mathrm{C}$ My parents want me to do it

- $\mathrm{C}$ My friend wants me to do it

- $\square$ I'm a junior or senior, and want to earn college credit with ISEF

- I I'm looking for a bigger challenge than my classes provide

\section{Do you have any questions about ISEF?}

Questions will be answered at your first advising appointment in October, or by email at the address you provided.

Are you working as part of a team? *

If 'no', then you can stop here.

- $\mathrm{Yes}$ 
- $\mathrm{No}$

Your partner's name?

First and last, please...

Your partner's grade level $(9,10,11$ or 12) in Fall $2013 ?$

Your partner's science teacher in Fall 2013?

Wilsonville AP Stats students choose 'Mr. Schauer'.

What class period does your partner have this teacher?

Your partner's phone number? Format \#\#\#-\#\#-\#\#\#\# please.

Your partner's preferred e-mail address

One that he/she will actually check! 
Appendix B. Weekly Meeting notes

Below is an example of meeting notes taken by me and/or the Program Coordinator during our scheduled meeting time with students. Student and teacher names have been replaced with pseudonyms to maintain confidentiality. Notes taken during meetings can be valuable to assess at what stage a student may be during their science fair process, what obstacles they are currently facing, and what support or interventions we may offer at that time.

\begin{tabular}{|c|c|c|c|c|}
\hline $\begin{array}{r}\text { Class } \\
\text { Period }\end{array}$ & \begin{tabular}{|r} 
Meeting \\
Time
\end{tabular} & $\begin{array}{l}\text { Student } \\
\text { Name* }\end{array}$ & Teacher* & Comments for September 23, 2013 meeting \\
\hline 3 & 10:40:00 & John & $\begin{array}{l}\text { Ms. } \\
\text { Smith }\end{array}$ & $\begin{array}{l}\text { video gaming effects on human performance, } \\
\text { gave him } 4 \text { things to do and a logbook. He is } \\
\text { looking for another variable or variables that } \\
\text { extend what we know about the effects of } \\
\text { gaming on humans. }\end{array}$ \\
\hline 3 & $10: 45: 00$ & Jessica & Mr. Boyd & $\begin{array}{l}\text { urbanization/stream ecology; Oregon City } \\
\text { Springwater environmental school k-8 (outdoor } \\
\text { school); 7th grade opal creek water quality } \\
\text { (measured by looking at invertebrates } \\
\text { (sensitivity to different factors); run-off from } \\
\text { non-porous surfaces, littering; natural versus } \\
\text { urban waterways - field-based study; talk about } \\
\text { getting in contact with Tryon Creek groups }\end{array}$ \\
\hline
\end{tabular}


Appendix C: ODE Science Inquiry and Engineering Design Scoring guides (20112012; High School level)

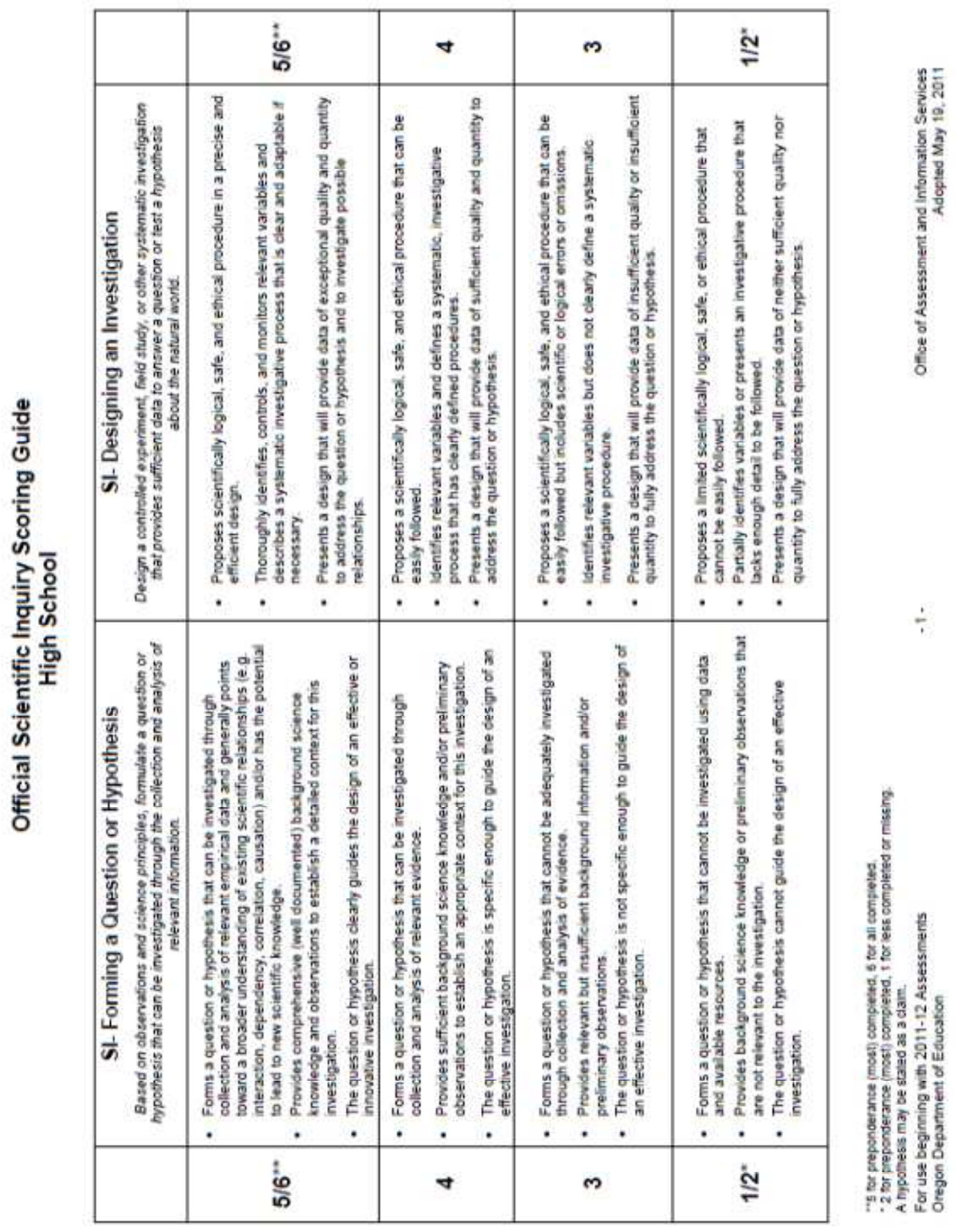




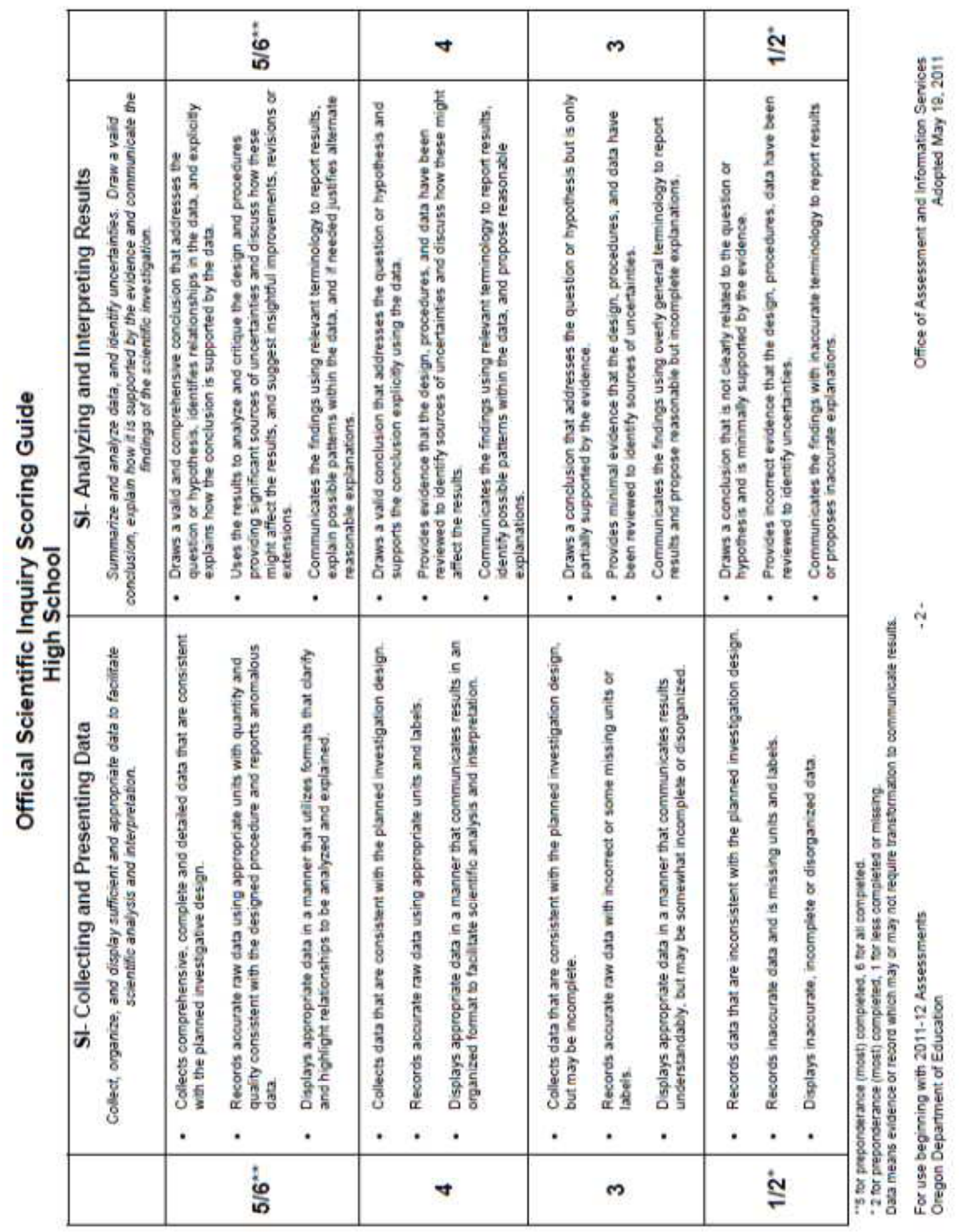




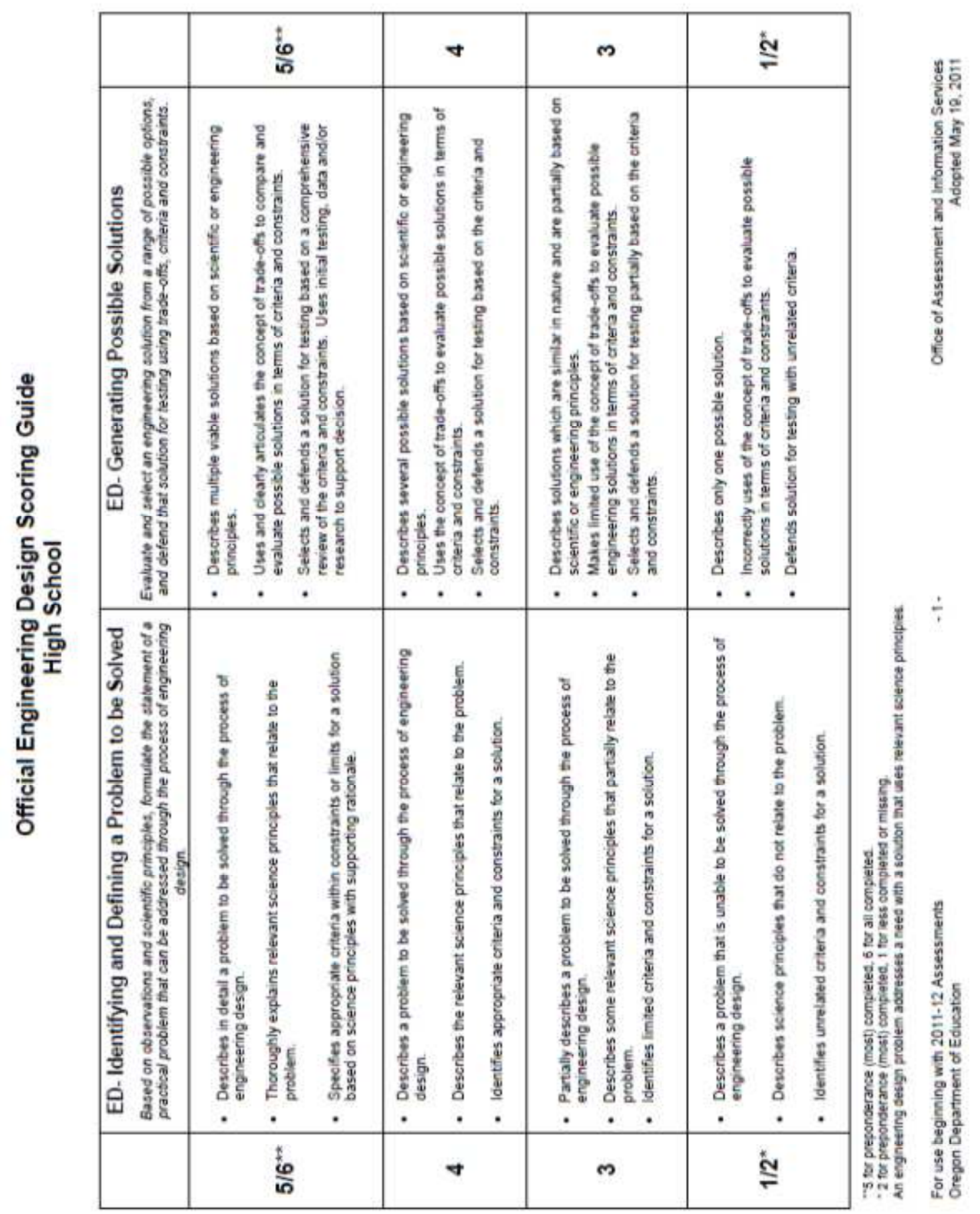




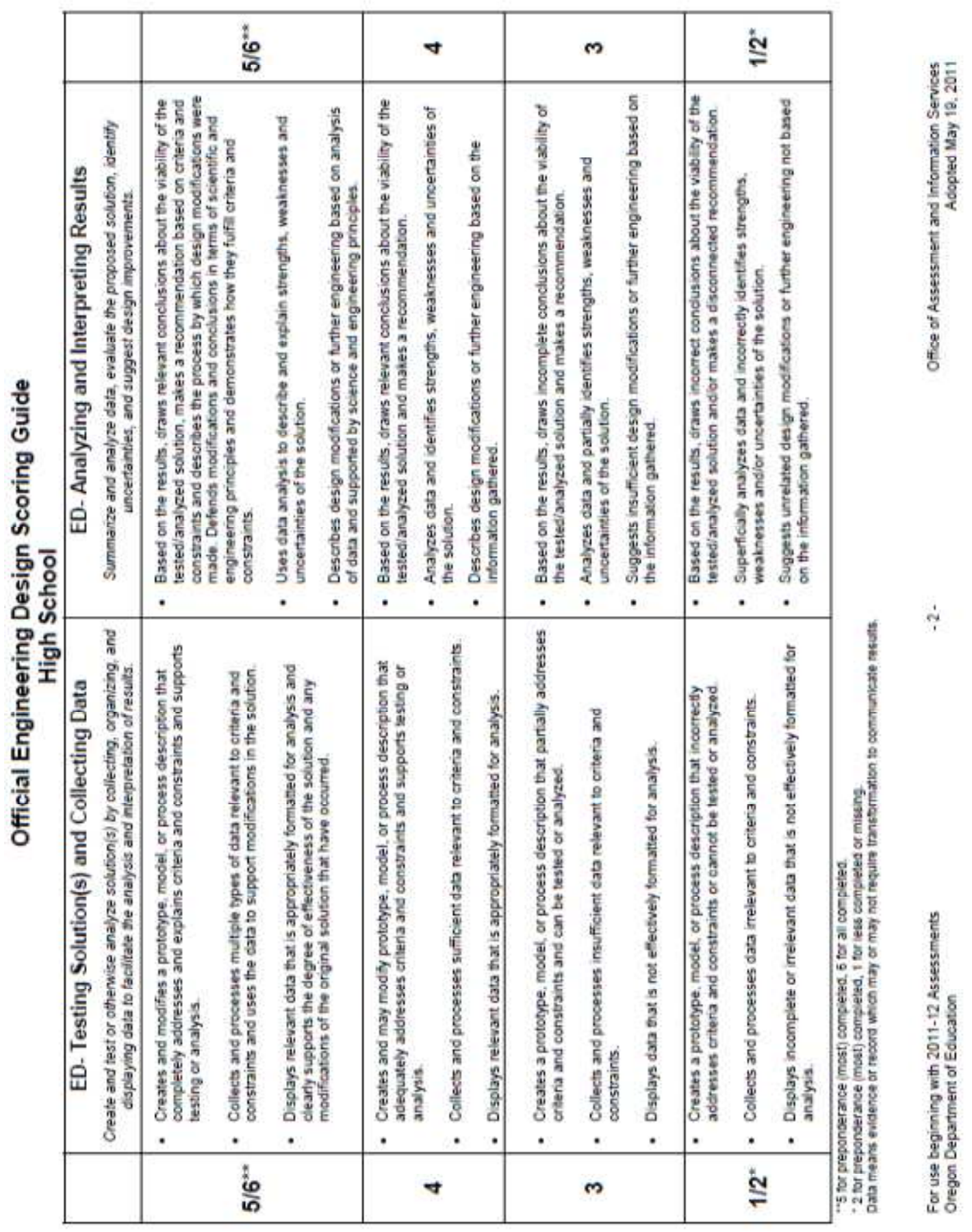




\section{Appendix D Program Assessment Survey}

\section{Program Assessment Survey (hosted by Qualtrics)}

Participation in this survey is voluntary, and anonymous. By taking part in this survey, I acknowledge that I am a willing participant and agree to have my responses included in the current research study.

1. Did you complete a science fair project this year (did you present your project at the CREST Jane Goodall Science Symposium)? Yes No

2. What was your original motivation for doing the science fair? [This question was asked during pre-registration and answered by all students]

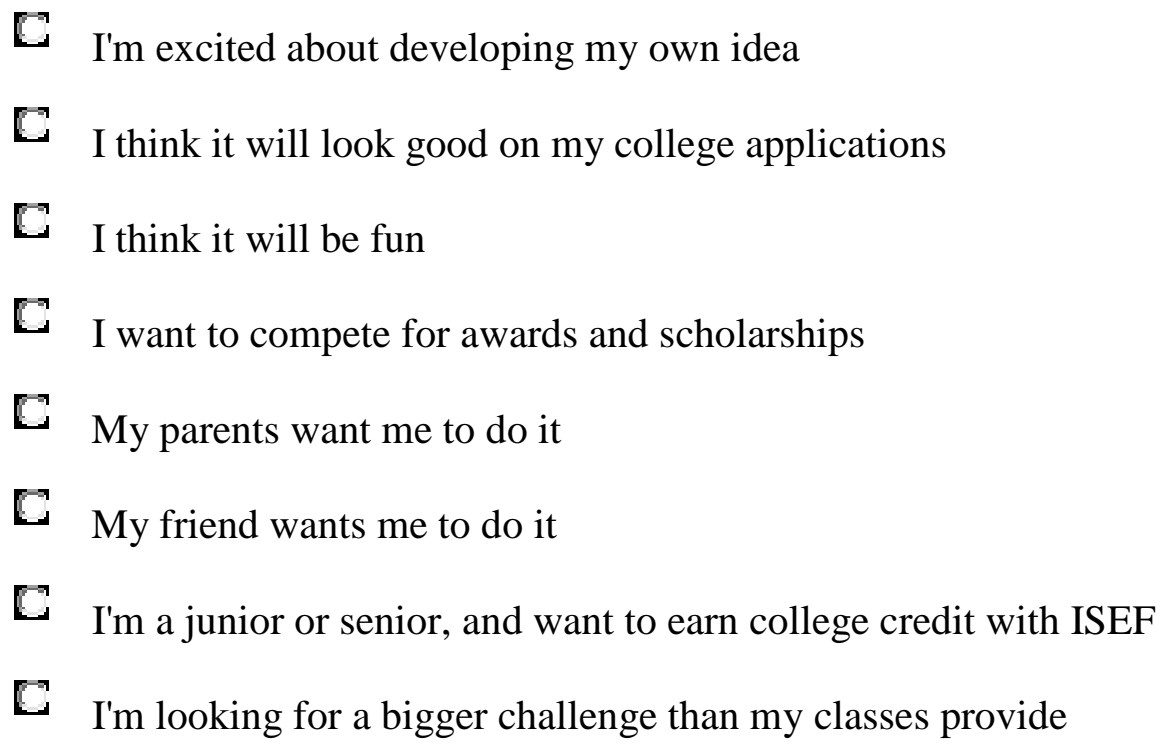

3. Based on your fair experience, do you feel that your original motivation was supported or satisfied? Explain.

4. Throughout the process, do you feel that your ISEF mentors established a positive environment for you to explore your ideas? Why or why not?

5. Please choose the most appropriate response for how helpful, or effective, each aspect of the ISEF program was to you 


\begin{tabular}{|c|c|c|c|}
\hline Not helpful/ & & Useful in & \\
\hline & Somewhat & combination & Very \\
\hline $\begin{array}{c}\text { did not } \\
\text { experience }\end{array}$ & helpful & $\begin{array}{l}\text { with other } \\
\text { methods }\end{array}$ & $\mathrm{d}$ \\
\hline
\end{tabular}

Informal discussions during ISEF

meetings

C $\quad$ C $\quad$ C $\quad$ C

Emails/phone calls/text messages

C $\quad$ C $\quad$ C $\quad$ C

Facebook page/'ISEF" Group page

C $\quad$ C $\quad$ C

Hand-outs provided/support documents

C $\quad$ C $\quad$ C

ISEF Timeline with explicit deadlines

C $\quad$ C $\quad$ C

Help with forms

C $\quad$ C $\quad$ C $\quad$ C

Gathering resources/materials

C $\quad$ C $\quad$ C $\quad$ C

Connecting to mentors/adult

sponsors/teachers

C $\quad$ C $\quad$ C $\quad$ C

Research Grant

C $\quad$ C $\quad$ C

Support with time management

C $\quad$ C $\quad$ C $\quad$ C

Support with judging/presenting (Mock)

C $\quad\left[\begin{array}{llll}a & \mathbb{C}\end{array}\right.$

Help with research plan/experimental design

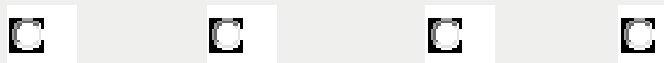


If you chose "Not Helpful" for any of the categories above, briefly explain why.

6. What additional support, if any, might you suggest as an improvement to the current program?

7. Which of these barriers did you face that made it difficult to finish your project?

Choose all that apply.

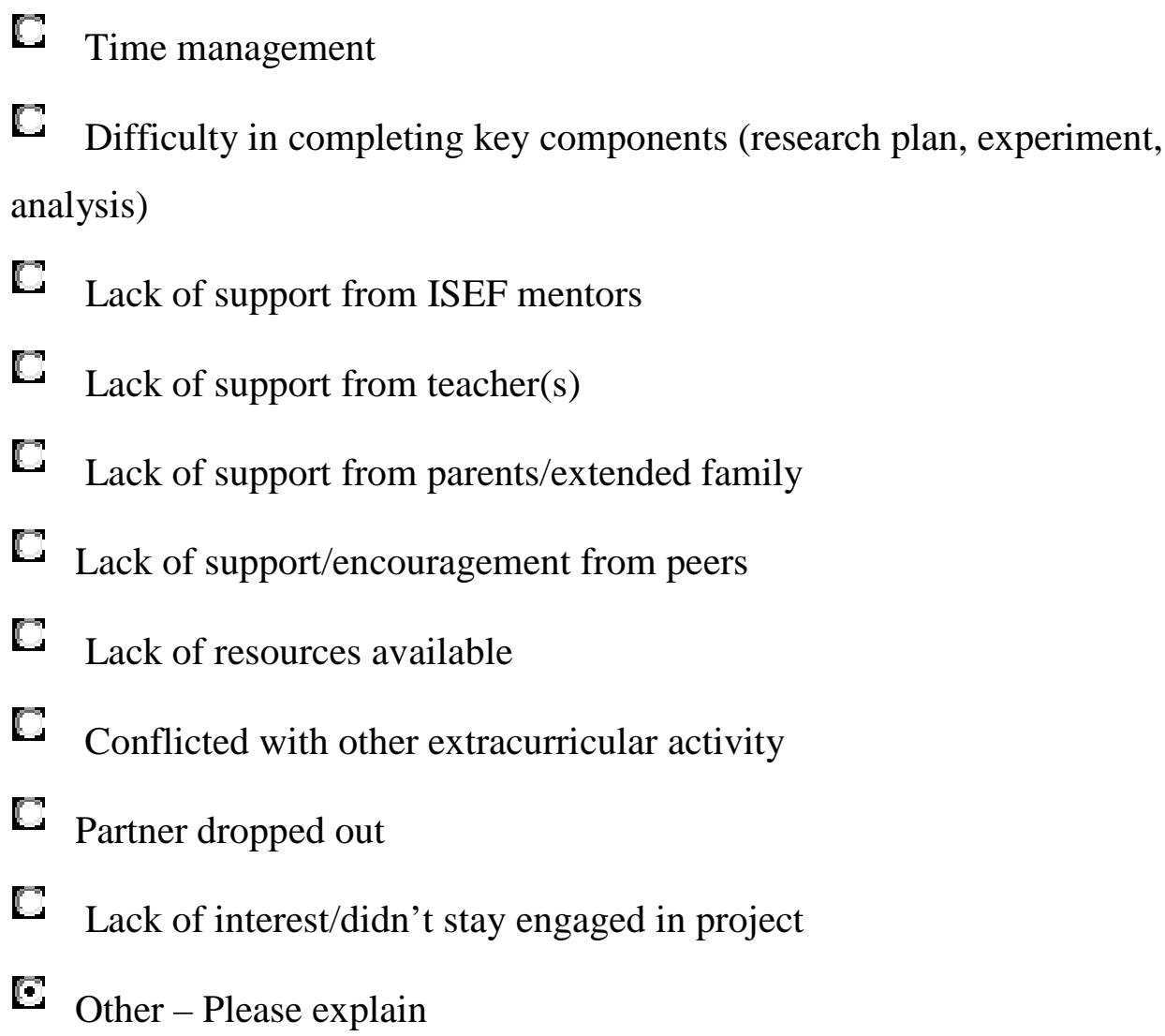

8. What was the most difficult barrier and why?

9. Overall, what was your impression of your science fair experience? 